\title{
Lifetime and residual strength of wood subjected to static and variable load
}

\author{
Nielsen, Lauge Fuglsang
}

Publication date:

1996

Document Version

Publisher's PDF, also known as Version of record

Link back to DTU Orbit

Citation $(A P A)$ :

Nielsen, L. F. (1996). Lifetime and residual strength of wood subjected to static and variable load. Tekst og Tryk A/S. Danmarks Tekniske Universitet. Institut for Baerende Konstruktioner og Materiale. Serie R No. 6

\section{General rights}

Copyright and moral rights for the publications made accessible in the public portal are retained by the authors and/or other copyright owners and it is a condition of accessing publications that users recognise and abide by the legal requirements associated with these rights.

- Users may download and print one copy of any publication from the public portal for the purpose of private study or research.

- You may not further distribute the material or use it for any profit-making activity or commercial gain

- You may freely distribute the URL identifying the publication in the public portal

If you believe that this document breaches copyright please contact us providing details, and we will remove access to the work immediately and investigate your claim. 
Institut for Bærende Konstruktioner og Materialer

Department of Structural Engineering and Materials

Danmarks Tekniske Universitet - Technical University of Denmark

Lifetime and residual strength of wood

subjected to static and variable load

\section{Lauge Fuglsang Nieisen}

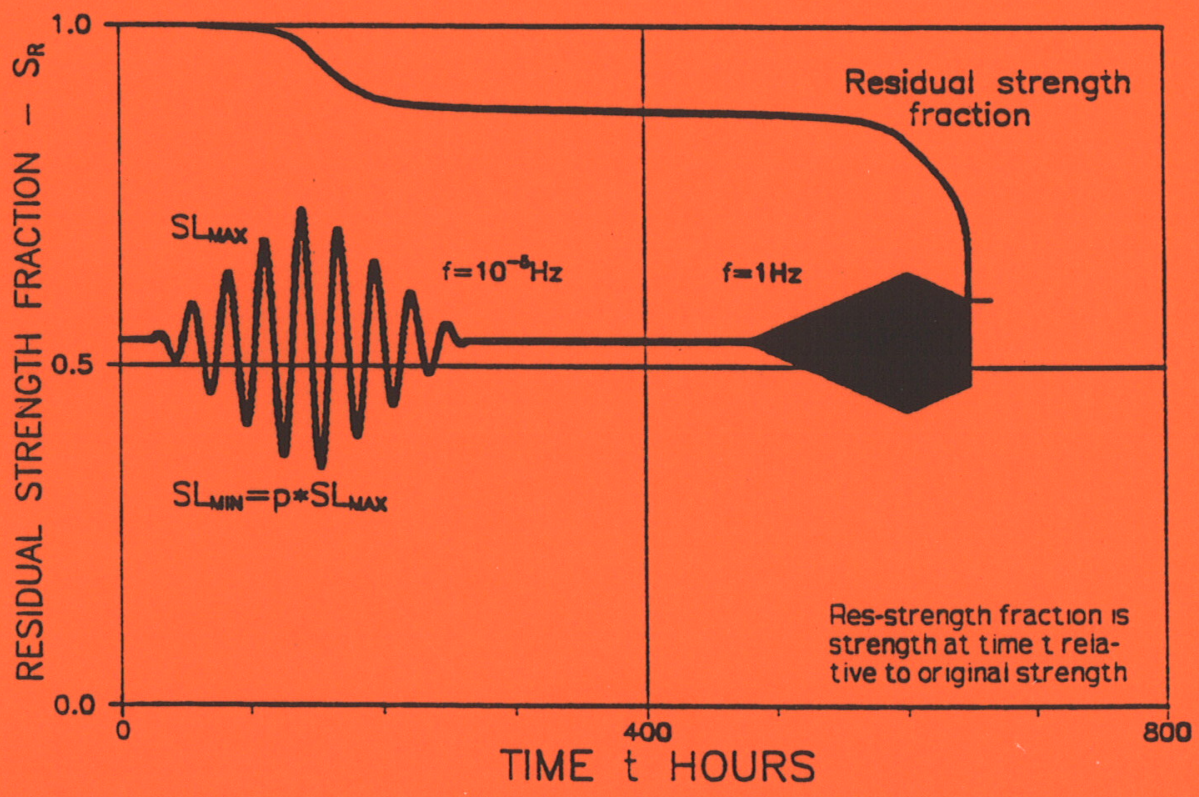

Residual strength and lifetime of wood loaded as indicated. Wood quality, $F L=0.4$ (clear wood). 


\section{Lifetime and residual strength of wood}

subjected to static and variable load

Lauge Fuglsang Nielsen

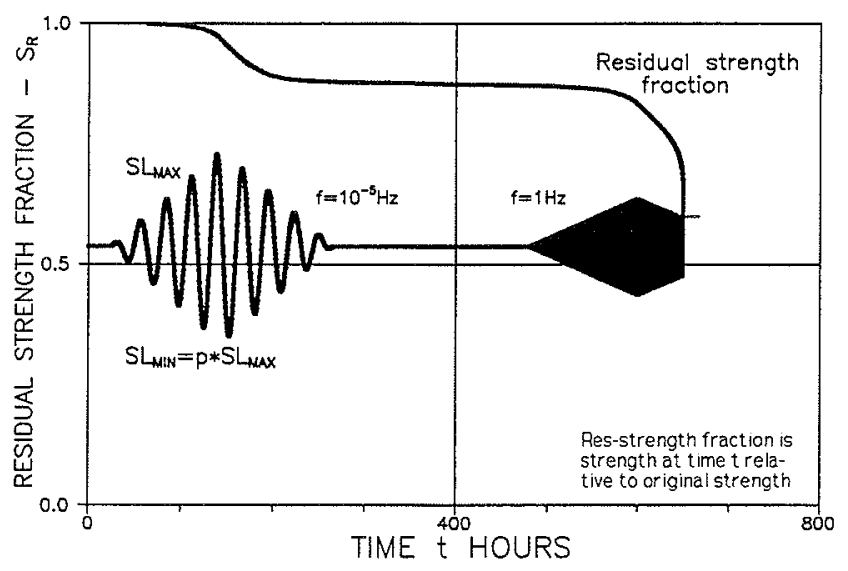

Residual strength and lifetime of wood loaded as indicated. Wood quality, $F L=0.4$ (clear wood). 
Lifetime and residual strength of wood subjected to static and variable load

Copyright (C) by Lauge Fuglsang Nielsen, 1996

Tryk:

Tekst \& Tryk

Danmarks Tekniske Universitet

Lyngby

ISBN 87-7740-185-9

ISSN 1396-2167

Bogbinder:

H. Meyer, Bygning 101, DTU 


\section{Abstract}

The DVM-theory (Damaged Viscoelastic Material) previously developed by the author to predict lifetime of wood subjected to static loads is further developed in this paper such that harmonic load variations can also be considered. Lifetime (real time or number of cycles) is predicted as a function of load amplitude, load average, fractional time under maximum load, and load frequency. The analysis includes prediction of residual strength during the process of load cycling. It is concluded that number of cycles to failure is a poor design criterion. A simple time criterion is much better. The theory is successfully compared with data from experiments representing different wood products. Master graphs are developed which can be used in fatigue design of wood products in general. These graphs are valid for any creep behavior (relaxation, moisture content) and materials quality (grading, strength level).

It is demonstrated how the theory developed can be generalized also to consider some non-harmonic load variations. An algorithm is presented for this purpose which might be suggested as a qualified alternative to the Palmgren-Miner's method normally used in fatigue analysis of materials under arbitrary load variations. The Palmgren-Miner's method has the disadvantage of not considering creep which may cause considerably overestimated time to failure, especially at low frequencies. Finally it is discussed how the theory can be generalized also to consider other materials such as concrete and other aging viscoelastic materials.

Keywords: Fatigue, Prediction, Lifetime, Residual strength, Variable load, Static load, Viscoelastic materials, Wood, Concrete.

\section{Résumé}

Den såkaldte DVM-teori (Damaged Viscoelastic Material) tidligere udviklet af forfatteren til prediktion af træs levetid under konstant last generaliseres i denne artikel til også at være gyldig for harmonisk varierende last. Levetiden (tid eller antal svingninger til brud) predikteres som funktion af lastamplitude, middellast, relativ tid under maximum last og lastfrekvens. Analysen medtager prediktion af reststyrken (genanvendelsesstyrken) som funktion af tid under svingningslast. Det påvises, at antal svingninger til brud er et dårligt designkriterium. Et simpelt tidskriterium er meget bedre. Der påvises god overensstemmelse mellem teoretisk predikterede levetider og levetider fra fors $\emptyset \mathrm{g}$ med forskellige træprodukter. Der udvikles standard-grafer til anvendelse for udmattelsesdesign af træprodukter i almindelighed. Disse grafer er gyldige for vilkårlig krybning (relaxationstid, fugtindhold) og trækvalitet (sortering, styrkeklasse).

Det demonstreres, hvordan den udviklede teory kan generaliseres til også at kunne tilgodese nogle klasser af ikke harmonisk varierende last. I den forbindelse præsenteres en computer-algoritme, der kunne foreslås som et kvalificeret alternativ til Palmgren-Miner's metode, der normalt anvendes i udmattelsesanalyser af materialer under varierende last. Palmgren-Miner's metode har den ulempe, at den ikke tilgodeser krybning, hvilket kan medføre betydelig overestimerering af levetid, specielt ved lave frekvenser. Sluttelig diskuteres det, hvordan teorien kan generaliseres til anvendelse på andre materialer som fex beton og andre ældende viskoelastiske materialer.

Nøgleord: Udmattelse, Prediktion, Levetid, Reststyrke, Varierende last, Statisk last, Viskoelastiske materialer, Træ, Beton. 



\section{Content}

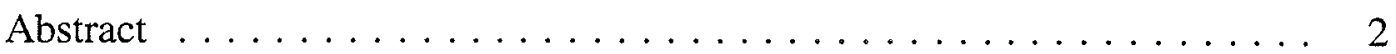

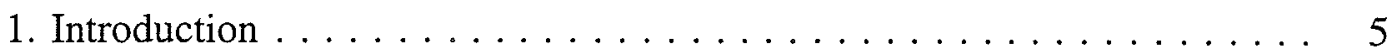

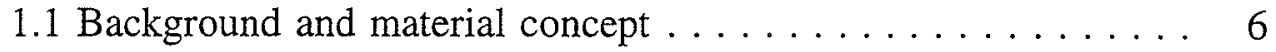

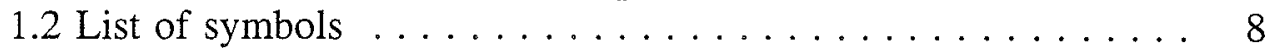

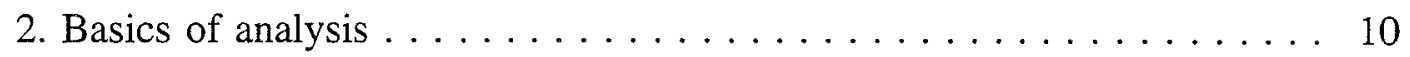

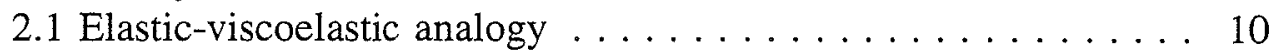

2.2 Creep . . . . . . . . . . . . . . . . . . . . . 10

2.3 Dugdale Crack . . . . . . . . . . . . . . . . 11

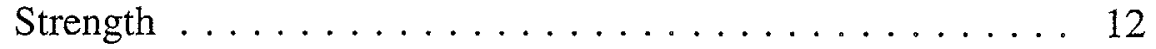

State of reference and extended crack ......... 13

Crack closure ...................... 13

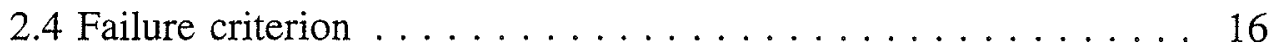

3. Elastic fatigue $\ldots \ldots \ldots \ldots \ldots \ldots \ldots \ldots \ldots \ldots \ldots \ldots$

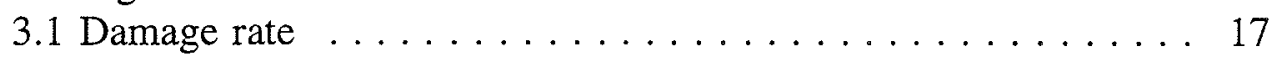

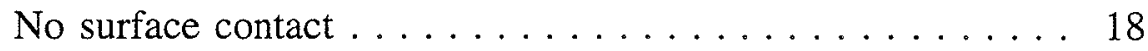

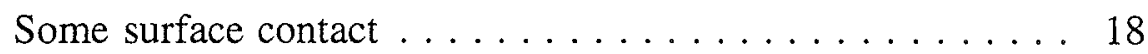

Material dependent surface contact . . . . . . . . 19

3.2 Lifetime . . . . . . . . . . . . . . . . . . . 20

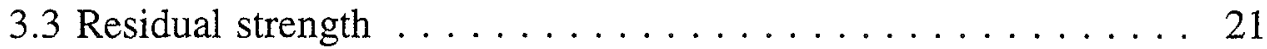

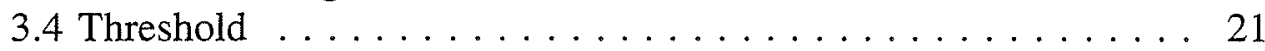

4. Viscoelastic fatigue . . . . . . . . . . . . . . . . . . . . 24

4.1 Model . . . . . . . . . . . . . . . . . . . . . . . 24

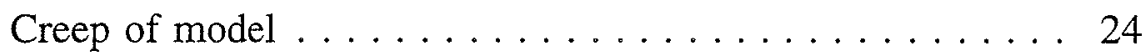

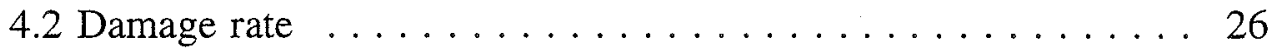

4.3 Lifetime and residual strength $\ldots \ldots \ldots \ldots \ldots \ldots \ldots \ldots$

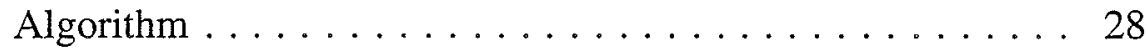

Endurance limit . . . . . . . . . . . . . . . . . 31

Generalized load history . . . . . . . . . . . . 31

4.4 Static load (dead load) $\ldots \ldots \ldots \ldots \ldots \ldots \ldots$

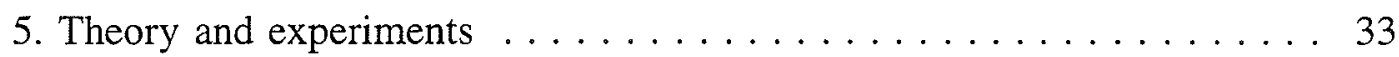

5.1 Preparation of algorithm $\ldots \ldots \ldots \ldots \ldots \ldots \ldots \ldots \ldots \ldots \ldots$

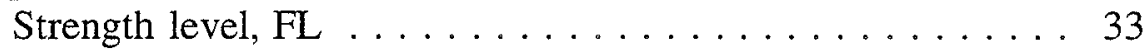

Load level, SL ................... 33

Damage rate power and damage rate constant ...... 34

Critical load ratio and threshold factor . . . . . . . . . . 34

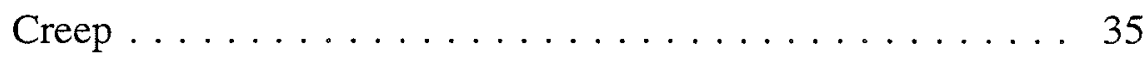

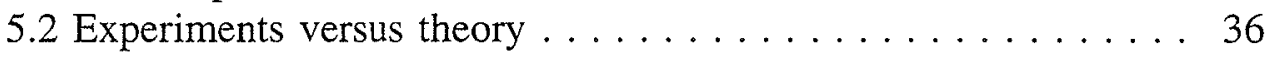

Special observations $\ldots \ldots \ldots \ldots \ldots \ldots \ldots \ldots$ 


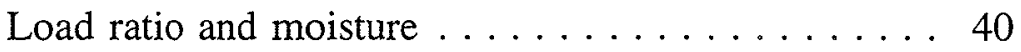

Peak loading . . . . . . . . . . . . . . 41

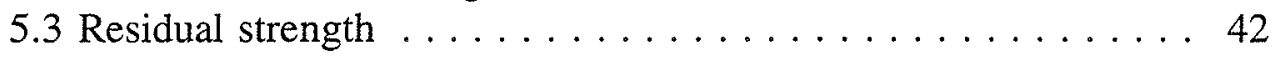

5.4 Discussion . . . . . . . . . . . . . . . . 43

6. Conclusions and final remarks . . . . . . . . . . . . . . . 44

6.1 Design - master graphs . . . . . . . . . . . . . . . . 45

6.2 Non-harmonic load variation $\ldots \ldots \ldots \ldots \ldots \ldots \ldots$

6.3 Other viscoelastic materials . . . . . . . . . . . 47

Glass fiber reinforced epoxy . . . . . . . . . 47

Aging viscoelastic materials - concrete . . . . . . . . 48

6.4 Some future research $\ldots \ldots \ldots \ldots \ldots \ldots . \ldots . \ldots 48$

Appendix A - Non-harmonic load variation . . . . . . . . . . 51

Literature .......................... 53 


\section{Introduction}

Fatigue in engineering material is usually defined as the progressive damage and failure that occurs when the material is subjected to repeated loads of a magnitude smaller than the static strength. This definition originates from early lifetime studies on elastic materials like many metals.

In the present paper where viscoelastic materials are considered the term fatigue has a broader meaning which at high frequency loading or in the absence of creep includes elastic fatigue - and at low frequency loading includes static fatigue which considers lifetime of viscoelastic materials subjected to constant loads.

Fatigue reduces the materials strength and lifetime to a degree which has to be considered in design of structures. The frequency of loading is a very important parameter when viscoelastic materials are considered. This has been strongly emphasized by the present author in (1). The number of load cycles to failure of wood, for example, may decrease more than 100 times lowering the frequency from 1 cycle per 10 seconds to 1 cycle per 2 hours. Thus, a number of cycles to failure is not a very good design criterion. A simple time criterion is much better. This fact which is considered in more details in this paper is often overlooked in fatigue research on building materials. One cannot in general accelerate fatigue tests on viscoelastic materials. Results needed for practical design can only be obtained involving theoretical research on the nature and mechanisms of the fatigue phenomenon. It is not, of course, realistic to think of experiments running under forecasted live conditions.

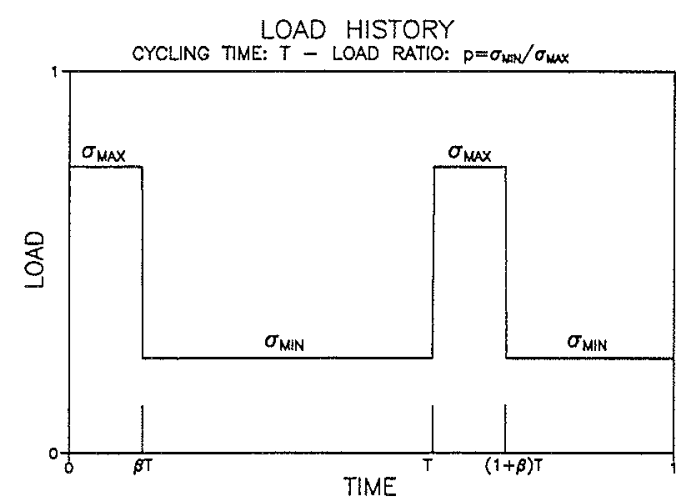

Figure 1. Basic load variation considered: Square wave loading.

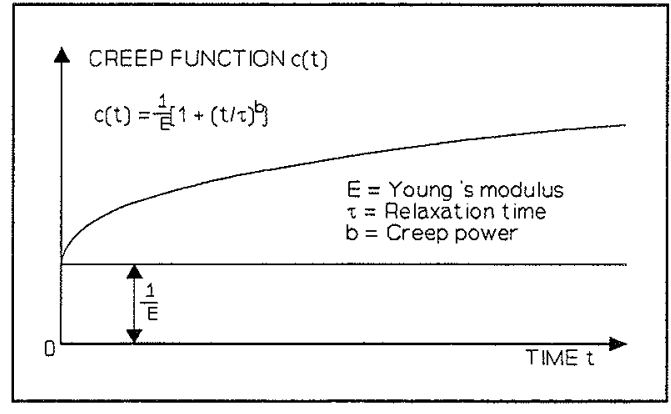

Figure 2. Creep function for materials with so-called Power-law creep.

Methods are developed in this paper which predict fatigue lifetime (real time or number of cycles) as well as remaining strength (residual) of viscoelastic materials subjected to variable loads or constant load. The paper is based on a study on 
wood fatigue previously presented in (1). Auxiliary basic research work is reported in $(2,3,4,5)$.

The basic load history considered in this paper is outlined in Figure 1. However, at the end of the paper (Section 6.2) it is demonstrated how the method developed can be generalized very easily such that some non-harmonic load variations can also be considered.

Viscoelastic materials considered are such which exhibit Power-law creep as defined in Figure 2. Quite a number of materials such as wood, wood based materials, polymers, and ceramic materials creep according to this "law" (6). Thus, the methods developed are quite general with respect to materials. Unless otherwise indicated, however, wood is always the prime material thought of in this paper. Nearly all material properties, applications, and examples presented refer to this material. It is, however, indicated at the end of the paper how the method can be modified to consider viscoelastic materials in general - also aging materials such as concrete.

\subsection{Background and material concept}

The fatigue analysis presented is based on exactly the same material concept which applies for the so-called DVM-theory previously developed by the author to describe the mechanical behavior of wood subjected to constant or nearly constant loads, see appendix of (7) for example. It is therefor appropriate to summarize very briefiy some basics of this theory:

Wood is a Damaged Viscoelastic Material the mechanical behavior of which can be determined by crack mechanical studies on an isotropic viscoelastic material with cracks perpendicular to load (opening mode cracks). Generality with respect to orthotropy is obtained introducing normalized load and material properties.

Normalized load SL (or load level) is load relative to strength in load direction. Normalized strength FL (or strength level or material quality) is strength in load direction relative to theoretical strength in that direction. Normalized creep is creep in load direction relative to flexibility (inverse stiffness) in that direction. Some modifications, however, have to be introduced which consider that creep at damage locations is not necessarily as measured on bulk volumes of material considered. Guide lines for modifications are presented in (7) which are also used in this paper. 
Application of the DVM-theory is not bound to a defect system which literally consists of cracks. Dislocations, for example, not visible to the naked eye may also be the defect source. It is known that the effects of a climbing group of edge dislocations are described exactly by the same equations which govern the crack problem. The DVM-theory is made general with respect to type of defects introducing non-dimensional "damages" (immediate crack length relative to initial crack length) in stead of cracks. Thus, failure mechanisms are also considered by the DVM-theory which are not associated with typical tensile crack surface textures. An example is wood in compression where failure expands along areas of buckling fibres.

The advantage of the DVM-theory to operate in general with non-dimensional load (SL) and non-dimensional materials quality (FL) means that these terms can often be evaluated in a generalized way involving load on structure and strength of structure in stead of stress and strength of material. For example, when load is a normal tensile force $\mathrm{P}$ on a cross-section of a pole we may consider $\mathrm{P}$ as a generalized load. Load level is $\mathrm{SL}=\mathrm{P} / \mathrm{P}_{\mathrm{CR}}$ and pole quality is $\mathrm{FL}=\mathrm{P}_{\mathrm{CR}} / \mathrm{P}_{\mathrm{L}}$ where $\mathrm{P}_{C R}$ and $\mathrm{P}_{\mathrm{L}}$ are tensile forces which produce short-time failure and theoretical failure (no cracks) of the pole, respectively.

The DVM-theory has recently been reviewed in (7) together with some examples illustrating the potentials of the theory to describe successfully wood mechanical phenomenons such as lifetime versus wood quality $(8,9,10)$, residual strength versus time under previous load (10), lifetime distribution versus strength distribution (11), and lifetime versus humidity. Strength reduction due to drying of wood is considered in (12).

The DVM-theory has the potential to operate with many interacting defects $(3$, 13,14). This feature is important in the analysis of macro stiffness and macro creep of wood. In strength analysis of wood, however, a single-crack model is justified as failure is very often observed to be released by single major defects. The lifetime studies previously referred to confirm that realistic lifetime predictions can be obtained on the basis of a single-crack materials concept.

The flexibility of the DVM-theory to consider simultaneously the influences on lifetime of loading, strength (materials quality, grading) and relaxation time (as influenced by moisture) makes the theory very qualified in the field of static fatigue of wood. Thus, it seems justified that the DVM-concept of wood is a realistic basis of developing further the theory such that fatigue lifetime under cyclic loading can also be considered. 


\subsection{List of symbols}

The symbols most frequently used in this paper are listed below. Load level and strength level are introduced relative to short time strength properties in load direction. Normalized creep is introduced relative to short time deformation in load direction. Normalized time related properties such as load frequency are introduced relative to creep relaxation time.

\section{Load and strength}

Load in general

Strength in load direction

Theoretical strength in load direction

Strength level

Load level

Minimum load

Minimum load level

Maximum load

Maximum load level

Load ratio

Load range

Load level range

\section{Damage}

Crack length

Initial crack length

Damage ratio (or just damage)

\section{Fatigue parameters}

Damage rate constant

Damage rate power

Contact parameter

Efficient parameter

\section{Stress intensity}

Stress intensity factor (SIF)

Critical SIF

Normalized SIF

Maximum SIF

Minimum SIF

SIF range

Normalized SIF range

Time and creep

Time in general

Creep function in load direction

Flexibility in load direction

Normalized creep function

Relaxation time (or doubling time)

Creep power

Time shift parameter $\sigma$

$\sigma_{\mathrm{CR}}$

$\sigma_{1}$

$\mathrm{FL}=\sigma_{\mathrm{CR}} / \sigma_{1}$

$\mathrm{SL}=\sigma / \sigma_{\mathrm{CR}}$

$\sigma_{\mathrm{MIN}}$

$\mathrm{SL}_{\mathrm{MIN}}=\sigma_{\mathrm{MIN}} / \sigma_{\mathrm{CR}}$

$\sigma_{\text {MAX }}$

$\mathrm{SL}_{\mathrm{MAX}}=\sigma_{\mathrm{MAX}} / \sigma_{\mathrm{CR}}$

$\mathrm{p}=\sigma_{\mathrm{MIN}} / \sigma_{\mathrm{MAX}}=\mathrm{SL}_{\mathrm{MIN}} / \mathrm{SL}_{\mathrm{MAX}}$

$\Delta \sigma=\sigma_{\text {MAX }}-\sigma_{\text {MIN }}=(1-p) \sigma_{\text {MAX }}$

$\Delta S L=S L_{\text {MAX }}-S L_{\text {MIN }}=(1-p) S L_{\operatorname{MAX}}$

1

$1_{0}$

$\kappa=1 / 1$ 。

C

$\mathrm{M}$

Z

$\mathrm{U}$

$\mathrm{K}=\sigma \sqrt{(}(\pi \mathrm{l})$

$\mathrm{K}_{\mathrm{CR}}=\sigma_{\mathrm{CR}} \sqrt{\left(\pi \mathrm{l}_{o}\right)}$

$\mathrm{K} / \mathrm{K}_{\mathrm{CR}}=\mathrm{SL} \sqrt{\mathrm{K}}$

$\mathrm{K}_{\mathrm{MAX}}=\sigma_{\mathrm{MAX}} \sqrt{(\pi \mathrm{l})}$

$\mathrm{K}_{\mathrm{MIN}}=\sigma_{\mathrm{MIN}} \sqrt{(\pi \mathrm{l})}$

$\Delta \mathrm{K}=\mathrm{K}_{\mathrm{MAX}}-\mathrm{K}_{\mathrm{MIN}}=\Delta \sigma \sqrt{(\pi \mathrm{l})}=(1-\mathrm{p}) \mathrm{K}_{\max }$ $\Delta \mathrm{K} / \mathrm{K}_{\mathrm{CR}}=\Delta \mathrm{SL} \sqrt{\mathrm{K}}=(1-\mathrm{p}) \mathrm{SL}_{\mathrm{MAx}} \sqrt{\mathrm{K}}$

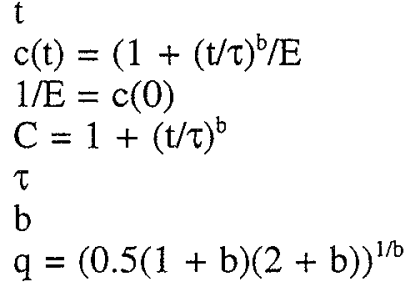


Time and load

Cycling time

Frequency

Number of load cycles

Fractional time under max load

Non-dimensional time

$\mathrm{T}$

$\mathrm{f}=1 / \mathrm{T}$

$\mathrm{N}=\mathrm{t} / \mathrm{T}=\mathrm{f}^{*} \mathrm{t}$

$\beta$

Non-dimensional frequency

$<\mathrm{t}\rangle=t / \tau$

$\langle\mathrm{f}\rangle=\tau^{*} \mathrm{f}=\tau / \mathrm{T}$ 


\section{Basics of analysis}

\subsection{Elastic-viscoelastic analogy}

The elastic-viscoelastic analogy $(15,16)$ is an important tool used in the present article to determine damage influence on the behavior of viscoelastic materials. The analogy can be formulated as follows: Similar solutions apply to a linear-elastic problem and to its exact but linear-viscoelastic duplicate. The only difference is that coefficients of elasticity in the elastic solution are represented by their viscoelastic counterparts (operators) in the viscoelastic solution.

This means, for example, that elastic displacements, $\mathrm{u}_{\mathrm{EL}}$, and viscoelastic displacements, $\mathrm{u}_{\mathrm{VISC}}$, are related by Equation 1 where $t$ is time and $\mathrm{C}(\mathrm{t})$ is the normalized creep function defined by $\mathrm{C}(\mathrm{t})=\mathrm{E}^{*} \mathrm{c}(\mathrm{t})$ where $\mathrm{E}$ and $\mathrm{c}(\mathrm{t})$ denote Young's modulus and the (conventional) creep function respectively.

$$
u_{V I S C}=\int_{-\infty}^{t} C(t-\theta) \frac{d u_{E L}}{d \theta} d \theta
$$

It is emphasized that the term "exact duplicate" includes boundary conditions which is of significance especially when moving cracks are considered as they are in this paper.

\subsection{Creep}

Wood and a number of other important building materials $(6,17)$ exhibit Power-Law creep which is generally described as follows in the literature,

$$
C(t)=1+a t^{b} \quad \text { with constants } a \text { and } b
$$

It has been shown by the present author (18) that this way of expressing creep is very unfortunate. No proper physical meaning can be given to the parameter a. A simple re-writing, however, was suggested in (18) which completely changes this feature. We re-phrase: Power law creep means that viscoelasticity is defined by a creep function of the type presented in Equation 2 and outlined in Figure 1 where $\tau$ and $b$ denote relaxation time (or creep doubling time) and creep power respectively,

$$
C(t)=1+\left(\frac{t}{\tau}\right)^{b}
$$


A complete rheological analysis of this expression has been made in (18). The relaxation time is sensitive to changes in temperature and humidity while the creep power, $b$, is practically independent of climatic conditions. The consequences of these observations are obvious: Standard lifetime solutions in $\langle t\rangle=t / \tau$ can be developed which are invariable with respect to moisture content, for example.

\subsection{Dugdale Crack}

It has been discussed in Section 1.1 that lifetime studies on wood can be made considering a single crack materials model. The model chosen in this work is

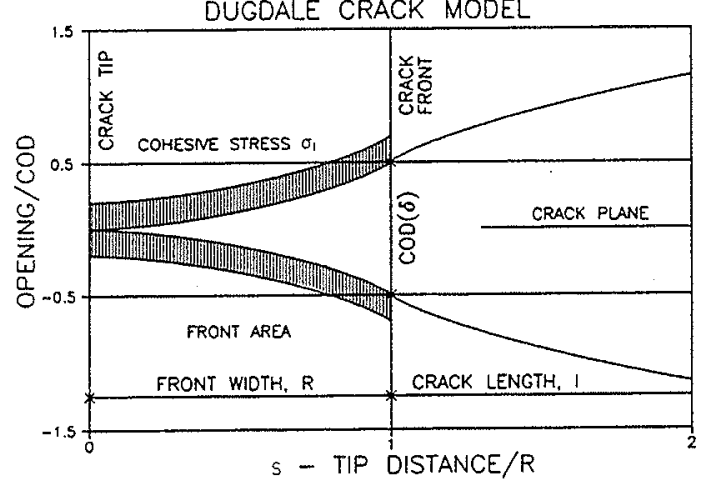

Figure 3. Dugdale crack model. Terminology used in the paper. based on the Dugdale crack (19) illustrated in Figure 3. Load, $\sigma$, is applied at infinity perpendicular to the crack plane. The uniformly distributed cohesive stress, $\sigma_{1}$, at the crack front may be thought of as being the un-cracked materials strength. (Material pulled out into the crack front zone is considered to be stiff and perfectly plastic). The width of the crack front zone, $\mathrm{R}$, and the crack front opening, $\delta$, are expressed as follows (plane stress solutions).

$$
\frac{R}{l}=\frac{\pi^{2}}{8}\left(\frac{\sigma}{\sigma_{l}}\right)^{2} ; \quad \frac{\delta}{l}=\frac{\pi \sigma^{2}}{E \sigma_{l}}
$$

Crack opening in general $\mathrm{v}$ and perpendicular to crack plane stress $\sigma_{Y}$ at the crack front are given by the following approximations presented in (2) introducing the non-dimensional coordinate, $\mathrm{s}=$ distance from crack tip divided by $\mathrm{R}$,

$$
\frac{v}{\delta} \approx\left(\begin{array}{ll}
0 & \text { when } s<0 \\
s^{2} & \text { when } 0 \leq s \leq 1 \\
2 \sqrt{s}-1 / s & \text { when } s>1
\end{array}\right.
$$




$$
\frac{\sigma_{Y}}{\sigma_{l}} \approx\left(\begin{array}{ll}
1-(2 / \pi) \arctan \sqrt{-s} & \text { when } s<0 \\
1 & \text { when } 0 \leq s \leq 1 \\
0 & \text { when } s>1
\end{array}\right.
$$

Two other parameters well-known from the crack mechanics literature (e.g. 20) are related to the crack front opening as shown in Equation 6 below. $\Gamma$ is strain energy release rate and $\mathrm{K}$ is stress intensity factor.

$$
\Gamma=\delta \sigma_{l}=\frac{\pi \sigma^{2} l}{E} \quad ; \quad K=\sqrt{E \Gamma}=\sigma \sqrt{\pi l}
$$

Remarks: The expressions presented apply for strength levels smaller than approximately $50 \%$. This restriction on the fatigue theory subsequently developed is of no practical significance as any wood material known to day have lower strength levels. It is noticed, however, that a generalization with respect to strength levels of the fatigue-theory subsequently presented is possible using the principles put forward. The mathematics to handle, however, becomes much more heavy (10). The Dugdale model works with the simplest possible distribution of cohesive stresses (uniform $\sigma_{1}$ ). Other distributions can be introduced (21). The changes of doing so, relative to the simple Dugdale results, are too small to justify the more complicated models - especially when recognizing that we know very little about the real stress distribution.

\section{Strength}

Strength, $\sigma_{\mathrm{CR}}$, of a cracked material is predicted by Equation 3 introducing the following failure criterion: A crack becomes unstable when the crack front opening, $\delta$, approaches a critical value, $\delta_{\mathrm{cr}}$. This criterion, sometimes named the critical COD (Crack Opening Displacement) criterion, can also be formulated with respect to critical strain energy release rate, $\Gamma_{C R}=\sigma_{1} \delta_{C R}$, or critical stress intensity factor, $\mathrm{K}_{\mathrm{CR}}=\sqrt{ }\left(\mathrm{E} \Gamma_{\mathrm{CR}}\right)$. Thus, strength of a material containing a crack of length 1 can be expressed as follows in three different ways all predicting a strength equal to the well-known Griffith load capacity (22).

$$
\sigma_{C R}=\sqrt{\frac{E \sigma_{l} \delta_{C R}}{\pi l}}=\sqrt{\frac{E \Gamma_{C R}}{\pi l}}=\frac{K_{C R}}{\sqrt{\pi l}} \quad \text { Strength }
$$




\section{State of reference and extended crack}

In the analysis of cracks with increasing lengths 1 it is very convenient to relate immediate crack properties to such properties of a reference crack of length $1_{0}$. For this purpose we re-introduce strength level and load level as follows together with damage ratio. The critical damage ratio, $\kappa_{C R}$, is damage ratio at which the material considered will fail when exposed to a load level, SL $\leq 1$.

$$
\begin{aligned}
& F L=\frac{\sigma_{C R}}{\sigma_{l}} ; S L=\frac{\sigma}{\sigma_{C R}} \text { with } \sigma_{C R} \text { at reference state, } l=l_{\circ} \\
& \kappa=\frac{l}{l_{0}} \text { with } 1 \leq \kappa \leq \kappa_{C R}=\frac{1}{S L^{2}} \quad \text { (damage ratio) }
\end{aligned}
$$

The following very useful expressions relating immediate crack opening to failure criterion can now be developed from the Dugdale solutions previously presented

$$
\frac{\delta}{\delta_{C R}}=\kappa S L^{2} \quad ; \quad \Gamma_{C R}=\frac{\sigma_{l} \delta}{\kappa S L^{2}}
$$

Another useful expression is presented in Equation 10. Residual strength fraction $S_{R}$ is strength remaining during crack propagation (crack length 1) relative to reference strength at initial crack length $1=1_{0}$.

$$
S_{R}=\frac{\sigma_{C R}(l)}{\sigma_{C R}\left(l_{0}\right)}=\frac{1}{\sqrt{\kappa}} \quad \text { (residual strength fraction) }
$$

Remark: It is noticed that a crack analysis based on the concept of a reference state is much better than based on measured fracture parameters $\Gamma_{\mathrm{CR}}$ or $\mathrm{K}_{\mathrm{CR}}$. $\mathrm{A}$ more direct and reliable "finger print" of the actual damage configuration in wood is obtained with strength measurements.

\section{Crack closure}

Until now it has been assumed implicitly that load (and consequently crack opening) is constant or increasing such that a uniformly distributed stress of cohesion agrees with the assumption of rigid-plastic materials behavior in the crack front zone. At decreasing load where the crack tries to return to its starting configuration this assumption cannot be maintained. Rice (23) modified the Dugdale solution also to consider a sudden reduction in load, $\Delta \sigma=\sigma_{\mathrm{MAX}}-\sigma_{\mathrm{MIN}}$, 
by superimposing (on the max load situation) a separate Dugdale load range solution where load is $-\Delta \sigma$ and cohesive stress is $-2 \sigma_{1}$. A compressive theoretical strength, $\sigma_{\mathrm{Cl}}=\sigma_{1}$, is hereby assumed. The results subsequently presented are reproduced from a Dugdale-Rice crack analysis made in (2) from which some results are illustrated in Figures 4 and 5. It is noticed that the width of the crack front zone and the crack front opening are still defined by the Dugdale solutions presented in Equation 3. Subscripts MAX and MIN are subsequently introduced as shown in Equation 11 to remember that a Dugdale-Rice crack closure model is considered.

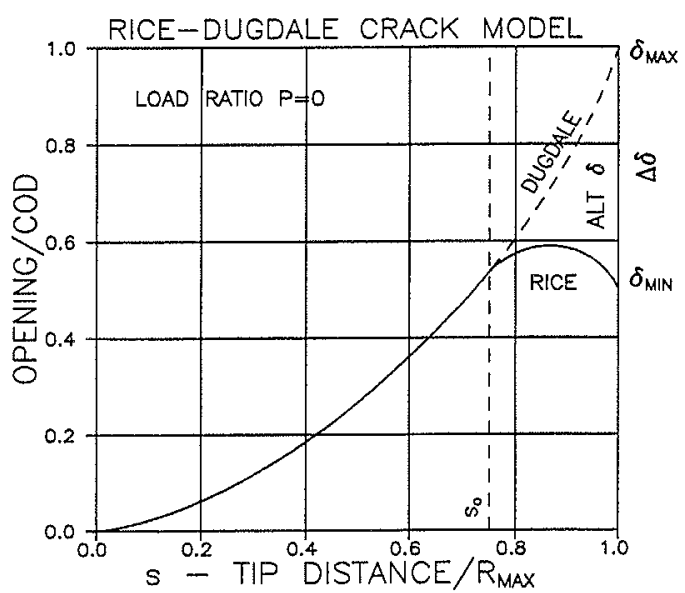

Figure 4. Crack opening predicted by the Rice crack closure model. Ex: $p=0$.

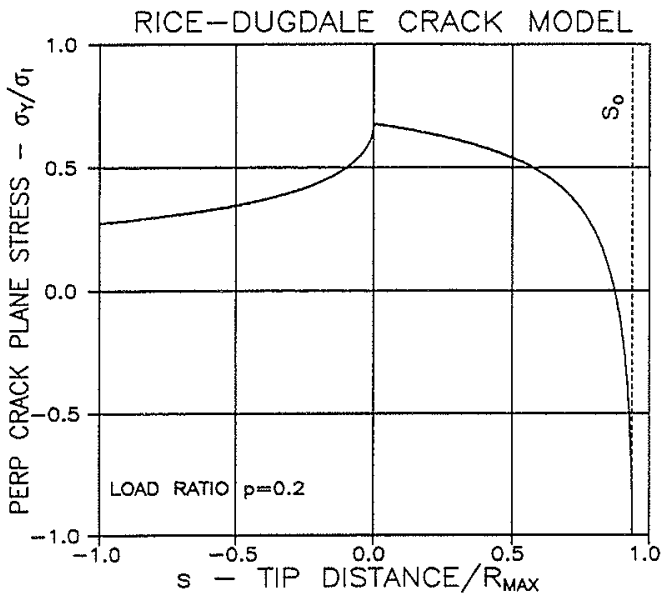

Figure 5. Crack plane stress predicted by the Rice crack closure model. Ex: $p=0.2$.

$$
\frac{R_{M A X}}{l}=\frac{\pi^{2}}{8}\left(\frac{\sigma_{M A X}}{\sigma_{l}}\right)^{2} ; \quad \frac{\delta_{M A X}}{l}=\frac{\pi \sigma_{M A X}^{2}}{E \sigma_{l}}
$$

Crack opening is invariant and equal to the Dugdale solution when $\mathrm{s} \leq \mathrm{s}_{\mathrm{o}}$ where

$$
1-s_{o}=\frac{1}{4}(1-p)^{2}
$$

Stress of cohesion is $-\sigma_{1}$ for $s \geq s_{0}$ and somewhere between $\sigma_{1}$ and $-\sigma_{1}$ at $s<s_{0}$, see Figure 5. The minimum crack front deformation $\delta_{\mathrm{MIN}}$ and the displacement range $\Delta \delta=\delta_{\mathrm{MAX}}-\delta_{\mathrm{MIN}}$ are given by

$$
\frac{\delta_{M I N}}{\delta_{M A X}}=1-\frac{1}{2}(1-p)^{2} \quad ; \quad \Delta_{o}=\frac{\Delta \delta}{\delta_{M A X}}=\frac{1}{2}(1-p)^{2}
$$


Rice's analysis disregards any contact of opposite crack surfaces at $s>1$ which means that the results are strictly valid only for load ratios $p \geq 0$. It is demonstrated in (2) that opposite crack surfaces start contacting each other at the crack centre at $\mathrm{p}=0$. The Rice results, however, present valuable qualitative information which must be considered in fatigue analysis. We continue accepting the existence of a coordinate, $s_{0}$, below which crack opening is invariant. An area of alternating deflection is defined at $s>s_{0}$ where stress of cohesion alternates between $\sigma_{1}$ and $-\sigma_{1}$. The actual quantities, however, or combination of quantities, $1-s_{0}$ and $\Delta \delta / \delta_{\max }$, are left to be deduced from experiments or other experiences revealing a so-called (surface) contact parameter $Z$ such that

$$
Z=\Delta_{o}\left(1-s_{o}\right) \quad ; \quad 1-s_{o}=\sqrt{\frac{Z}{2}} ; \Delta_{o}=\frac{\Delta \delta}{\delta_{M A X}}=\sqrt{2 Z}
$$

The concept of a contact parameter $Z$ to group an quantify crack closure penomenons was introduced into fatigue studes by the author in (1). The contact parameter of the Rice model is given by the first expression in Equation 15 .

In practice the phenomenon of crack surfaces contacting each other outside the crack front area is a reality even if $\mathrm{p}>0$. When running cracks are considered new crack surfaces of destroyed material created in the process of crack propagation are very likely to produce contact at decreasing load. This feature which was first brought to attention by Elber (24) has been considered theoretically by the present author in (2, Section 3.3.2) with the result that some crack surface contact outside the crack front area can be considered by the Rice solutions only by replacing the load ratio $p$ with $p \approx\left(1+p^{2}\right) / 2$. Then $\mathrm{Z}$ becomes the latter expression in Equation 15. The assumption of $\mathrm{p} \geq 0$ still applies. Negative load ratios can to day only be considered introducing empirical evidence into Equation 14. This point is discussed in more details in Chapter 3.

$$
Z=\left(\begin{array}{ll}
\frac{(1-p)^{4}}{8} & \text { No crack surface contacts } \\
\frac{\left(1-p^{2}\right)^{4}}{128} & \text { Some crack surface contacts }
\end{array}\right.
$$




\subsection{Failure criterion}

The failure criterion previously applied to predict strength is generalized as follows to apply also when loads are alternating. A stiff-plastic front zone behavior is hereby assumed in both tension (yield stress $\sigma_{1}$ ) and compression (yield stress $\left.-\sigma_{1}\right)$.

Failure appears when total energy dissipation at the crack front approaches the critical energy release rate previously introduced. The failure criterion is illustrated in Equation 16 looking at the number of load cycles $\mathrm{N}=\mathrm{N}_{\mathrm{S}}$ a resting crack with $\kappa \equiv 1$ can withstand before failure starts. The critical strain energy release rate introduced is from Equation 9 with $(\delta, \kappa, S)=\left(\delta_{\operatorname{MAX}}, 1, \mathrm{SL}_{\mathrm{MAX}}\right)$.

$$
\begin{aligned}
& \Gamma=\left(\delta_{M A X}+2 N \Delta \delta\right) \sigma_{l}=\delta_{M A X} \sigma_{l}\left(1+2 N \Delta_{o}\right)=\delta_{M A X} \sigma_{l}(1+2 N \sqrt{2 Z}) \\
& \Rightarrow \Gamma_{C R}=\frac{\sigma_{l} \delta_{M A X}}{S L_{M A X}^{2}} \Rightarrow N_{S}=\frac{1-S L_{M A X}^{2}}{2 S L_{M A X}^{2} \sqrt{2 Z}}
\end{aligned}
$$

Remark: It is noticed that number of cycles to failure initiation $N_{S}$ is ignored in the present lifetime analysis as it is much smaller in most practice than total number of cycles $\mathrm{N}_{\mathrm{CAT}}$ leading to catastrophic materials failure. 


\section{Elastic fatigue}

\subsection{Damage rate}

The rate of damage in an elastic material subjected to varying loads can be determined as follows: We consider a location, $X$, defined by the immediate crack tip. The propagating crack will open up this location such that coherence fails after a period of time, $\Omega$, which can be determined, as subsequently explained, considering the energy dissipation involved in the opening process. The associate distance travelled by the crack is equal to the immediate crack front width, $R_{M A X}$, meaning that crack (and damage) velocity is given by

$$
\frac{d l}{d t}=\frac{R_{M A X}}{\Omega} \Rightarrow \frac{d \kappa}{d N}=\frac{\pi^{2} F L^{2}}{8} \frac{\kappa S L_{M A X}^{2}}{\Omega / T}
$$

Assuming a locally constant rate of propagation position $\mathrm{X}$ will experience an opening history which can be subdivided in two parts: 1) a parabolically

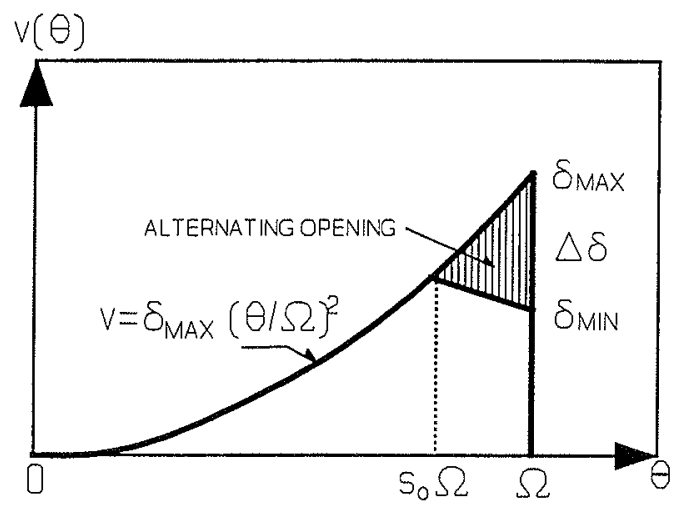

Figure 6. Opening history of a position being penetrated by a crack. increasing opening history starting with $\delta=0$ at time 0 and finishing with $\delta_{\mathrm{MAX}}$ at time $\Omega$ (so far unknown) where the crack front is at position $X$ - and 2) an alternating opening history starting with 0 amplitude at time $\left(1-\mathrm{s}_{\mathrm{o}}\right) \Omega$ and approaching an amplitude of $\Delta \delta$ at time $\Omega$. The amplitudes are approximated to vary linearly between $\left(1-s_{0}\right) \Omega$ and $\Omega$. The energy dissipated at position $\mathrm{X}$ in this process is given by

$$
\Gamma=\sigma_{l} \delta_{M A X}\left[1+\frac{\Delta \delta}{\delta_{M A X}}\left(1-s_{o}\right) \frac{\Omega}{T}\right]=\sigma_{l} \delta_{M A X}\left(1+Z \frac{\Omega}{T}\right)
$$

where the terms in order correspond to the opening histories 1 and 2 just considered. (Time under alternating opening is $\left(1-\mathrm{s}_{\mathrm{o}}\right) \Omega$. Each cycling time, $\mathrm{T}$, contributes to dissipation with $2 \Delta \delta \sigma_{1}$. Average amplitude is $\Delta \delta / 2$ ).

As the crack front of a propagating crack is continuously failing we may determine $\Omega$ from Equation 18 introducing $\Gamma=\Gamma_{\mathrm{CR}}$ expressed by Equation 9 with $(\delta$, $\mathrm{SL})=\left(\delta_{\mathrm{MAX}}, \mathrm{S}_{\mathrm{MAX}}\right)$. We get 


$$
\frac{1-\kappa S L_{M A X}^{2}}{\kappa S L_{M A X}^{2}}=Z \frac{\Omega}{T}
$$

from which the crack velocity expressed by Equation 17 can be written as follows where stress intensity factors have been introduced from the list of symbols presented in Section 1.

$$
\frac{d \kappa}{d N}=\frac{\pi^{2} F L^{2}}{8} \frac{\left(S L_{M A X}\right)^{4} \kappa^{2}}{1-\kappa S L_{M A X}^{2}} Z=\frac{\pi^{2} F L^{2}}{8} \frac{\left(\Delta K / K_{C R}\right)^{4}}{1-\left(K_{M A X} / K_{C R}\right)^{2}} \frac{Z}{(1-p)^{4}}
$$

This expression forms the basis of damage rate prediction. The type of crack surface contact outside crack front areas is considered by the contact parameter $\mathrm{Z}$ :

\section{No surface contact}

If there is no surface contact we introduce the contact parameter $\mathrm{Z}$ presented by the former expression in Equation 15. The following expression is obtained with with load level range $\Delta S L$ introduced as defined in the list of symbols presented in Section 1.2.

$$
\frac{d \kappa}{d N}=\frac{\pi^{2} F L^{2}}{64} \frac{(\Delta S L)^{4}}{1-\kappa S L_{M A X}^{2}} \kappa^{2}=\frac{\pi^{2} F L^{2}}{64} \frac{\left(\Delta K / K_{C R}\right)^{4}}{1-\left(K_{M A X} / K_{C R}\right)^{2}}
$$

Except for the constant (96 in stead of 64) the latter expression in Equation 21 agrees with an expression obtained by Weertman (25) on the basis of dislocation theory. Rice (23) used his own crack closure theory to derive $\mathrm{dl} / \mathrm{dN}=$ constant* $(\Delta \mathrm{K})^{4}$ which also compares positively with Equation 21 .

\section{Some surface contact}

If there is some surface contact the following damage rate is obtained by Equation 20 introducing the contact parameter $Z$ by the latter expression in Equation 15 .

$$
\begin{aligned}
& \frac{d \kappa}{d N}=\frac{\pi^{2} F L^{2}}{64} \frac{(U \Delta S L)^{4}}{1-\kappa S L_{M A X}^{2}} \kappa^{2}=\frac{\pi^{2} F L^{2}}{64} \frac{\left(U \Delta K / K_{C R}\right)^{4}}{1-\left(K_{M A X} / K_{C R}\right)^{2}} \\
& \text { with efficient factor } U=U(p)=\frac{1+p}{2}
\end{aligned}
$$


This expression agrees very positively with the empirically based, so-called $\mathrm{Pa}-$ ris-Erdogan-Elber Law $(26,29)$

$$
\frac{d l}{d N}=A(U \Delta K)^{M} \quad(\text { Paris-Erdogan-Elber-Law })
$$

which is very often met in the experimental literature on fatigue of materials (e.g. $27,28)$ - especially metals - where it frequently produces an excellent data fit. "A" is a materials "constant" which, however, to some degree is dependent on load level. The efficiency factor $U$ is also material dependent. Elber (29) suggested $U \approx 0.5+0.4 p$ on the basis of data from experiments $(p \geq-0.1)$ on aluminum. $M$ is a constant which for a number of metals has a magnitude close to 4. Many materials, however, exhibit M-values significantly different from 4. M $\approx 2.3$ was observed for a special steel in (30). The main rule seems to be $M \geq$ 4 (31). For example, $M \approx 5$ and $M \approx 8.5$ were obtained for some polymers (32) and wood respectively (33). The hypothesis is suggested by author in () that $M$ is texture dependent such that $M$ increases with increasing roughness of the failure surface.

Remark: The results obtained by Elber indicate that Equation 23 can also be used for negative load ratios. We proceed assuming that this is true.

\section{Material dependent surface contact}

The quality of the Paris-Erdogan-Elber Law to fit data (where $\sigma_{\text {MAX }}$ is not too close to $\sigma_{\mathrm{CR}}$ ) is generally so convincing that any theory developed in the area of fatigue must be able of "predicting" it. Thus, from comparing Equations 20 and 23 we suggest

$$
Z=\frac{C}{8}(1-p)^{4} U^{M}\left(\frac{\Delta K}{K_{C R}}\right)^{M-4}=\frac{C}{8}[U(1-p)]^{M}\left[\kappa S L_{M A X}^{2}\right]^{M / 2-2}
$$

where the damage rate constant $C$ and the damage rate power $M$ are considered to be material dependent fatigue parameters which can be determined from experiments as subsequently shown in Section 5.1.

Damage rate can now be expressed by the following expression obtained from Equation 20 with contact parameter $\mathrm{Z}$ introduced as just suggested. This expression which complies well with the Paris-Erdogan-Elber expression forms the elastic fatigue basis in the subsequent viscoelastic fatigue analysis. 


$$
\frac{d \kappa}{d N}=\frac{C \pi^{2} F L^{2}}{64} \frac{\left(U \Delta K / K_{C R}\right)^{M}}{1-\left(K_{M A X} / K_{C R}\right)^{2}}=\frac{C \pi^{2} F L^{2}}{64} \frac{(U \Delta S L)^{M}}{1-\kappa S L_{M A X}^{2}} \kappa^{M / 2}
$$

The efficiency factor $1 \geq U \geq 0$ is a measure of the efficiency of the crack closure mechanism. The $\delta$-range $\Delta \delta$ decreases with decreasing $U$ which decreases crack velocity. The following efficiency factor is suggested,

$$
U=0.5\left(\begin{array}{ll}
\operatorname{Max}[1,1+p] & \text { when } p \geq p_{C R} \\
\operatorname{Min}\left[1,\left(1-p_{C R}\right) /(1-p)\right] & \text { when } p<p_{C R}
\end{array}\right.
$$

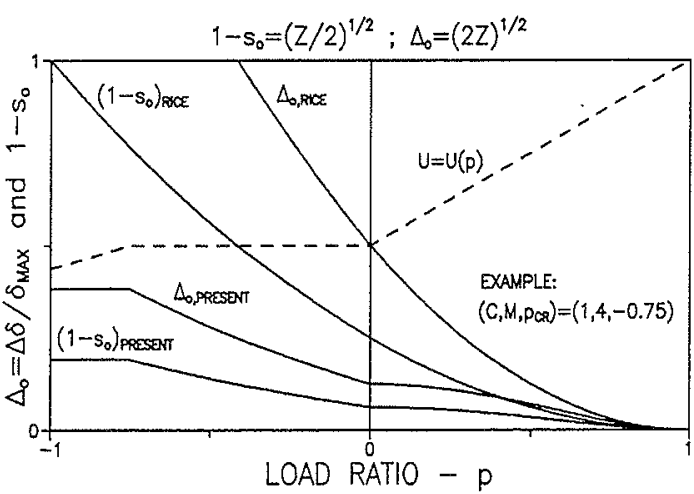

Figure 7. Efficiency factor $U$ and its influence on crack closure. where $p_{C R}$ is a critical load ratio below which lifetime is predicted to be independent of $\mathrm{p}$ (see subsequent Equations 27 and 28). The efficiency factor suggested agrees well with the factor previously referred to as determined experimentally by Elber (29) and theoretically by the present author, see Equation 22. The influence of the efficiency factor on the crack closure geometry at the crack front is illustrated in Figure 7.

\subsection{Lifetime}

Equations 25 can be solved analytically with respect to lifetime, $\mathrm{N}_{\mathrm{CAT}}$, integrating between $\kappa=1$ and $\kappa=\kappa_{\mathrm{CR}}=1 / \mathrm{S}_{\mathrm{MAX}}{ }^{2}$. The results such obtained are presented in Equation 27 with examples illustrated by master graphs in Figure 8.

$$
\begin{aligned}
& N_{C A T}=\frac{1}{G S L_{M A X}^{2}}\left[\frac{1-S L_{M A X}^{M-2}}{(M-2) S L_{M A X}^{M-2}}-\frac{1-S L_{M A X}^{M-4}}{(M-4) S L_{M A X}^{M-4}}\right] \\
& N_{C A T}=\frac{1}{G S L_{M A X}^{2}}\left[\frac{1}{S L_{M A X}^{2}}-1+\log _{E}\left(S L_{M A X}\right)\right] \quad(M=4)
\end{aligned}
$$

with $\quad G=\frac{C F L^{2}}{13}[U(1-p)]^{M}$ 


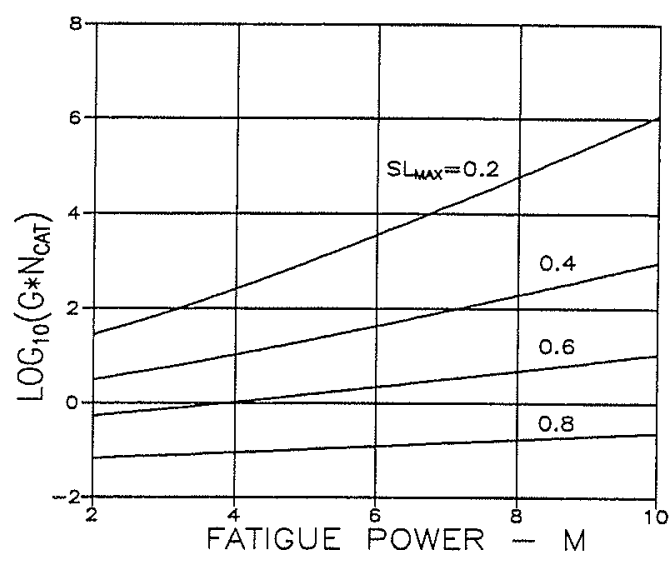

Figure 8. Lifetime as a function of fatigue power $M$.

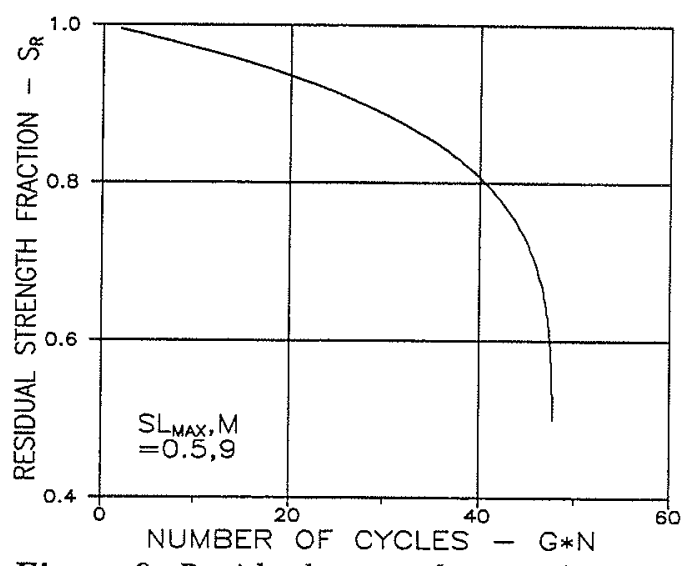

Figure 9. Residual strength as a function of number of load cycles.

\subsection{Residual strength}

The materials strength decreases during the process of fatigue. The (relative) strength, $S_{R}$, still remaining after a certain number of load cycles $\mathrm{N}$ - where damage ratio has become $\kappa=\kappa(N)$ - is described very easily by Equation 10 . This means $S_{R}=1 / \sqrt{k}$ which leads to the following relation integrating Equation 25 between $\kappa=1$ and $\kappa=1 / S_{R}{ }^{2}$. Residual strength can also be presented by master graphs as illustrated in Figure 9.

$$
\begin{aligned}
& N=\frac{1}{G S L_{M A X}^{2}}\left[\begin{array}{l}
\frac{1-S_{R}^{M-2}}{(M-2) S L_{M A X}^{M-2}}-\frac{1-S_{R}^{M-4}}{(M-4) S L_{M A X}^{M-4}}
\end{array}\right] \\
& N=\frac{1}{G S L_{M A X}^{2}}\left[\begin{array}{l}
\frac{1-S_{R}^{2}}{S L_{M A X}^{2}}+2 \log _{E}\left(S_{R}\right)
\end{array}\right] \quad(M=4)
\end{aligned}
$$

\subsection{Threshold}

There are many speculations on the existence of a threshold on load alternation below which no fatigue failure will ever occur in wood and other viscoelastic materials. Information given by Kollmann and Côté (34, Table 7.21) indicate a threshold load level ("endurance limit") of $S_{T H} \approx 1 / 4-1 / 3$ for wood. Kollmann and Côté state that the endurance limit for wood seems to be "as a rule higher than for most metals". Their conclusions seem to presume that threshold is load level below which the wood tested will survive $10^{6}-10^{7}$ cycles. The data con- 
sidered were from tests made at relatively high load frequencies ( $f>15 \mathrm{~Hz}$ ). No experimental evidence is present which supports the threshold idea at arbitrary load frequencies.

The existence of a threshold is widely accepted in the literature on metal fatigue. Irving and McCartney (27) suggested on an empirical basis that the threshold phenomenon can be considered practically by replacing the stress range intensity factor in Equation $23(\mathrm{M}=4)$ such that $\Delta \mathrm{K}^{4}$ becomes $\Delta \mathrm{K}^{2} *\left(\Delta \mathrm{K}^{2}-\Delta \mathrm{K}_{\mathrm{TH}}{ }^{2}\right)$ where a threshold stress intensity factor range, $\Delta \mathrm{K}_{\mathrm{TH}}$, is introduced as a materials constant. Information given in (27) indicate $\Delta \mathrm{K}_{\mathrm{TH}} / \mathrm{K}_{\mathrm{CR}} \approx 10 \%$. Examples given in (35) demonstrate, however, that $\Delta \mathrm{K}_{\mathrm{TH}}$ cannot in general be considered as a materials constant.

In the authors opinion we still have to wait for convincing experimental evidence on the existence of an endurance limit for wood. At the present it is a matter of belief whether or not such limit exists - and, if it exists - can be associated with some mechanism or natural explanation. The hypothesis is suggested in this paper that there is a threshold parameter $\mathrm{D}_{\mathrm{TH}}=\left(\Delta \delta / \delta_{\mathrm{CR}}\right)_{\mathrm{TH}}$ on $\mathrm{D}=\Delta \delta / \delta_{\mathrm{CR}}$ below which the development of alternating crack opening $(\Delta \delta)$ is suppressed even more than predicted by the efficiency factor $U$ in Figure 7 . No special analytical precautions are needed when

$$
D=\frac{\Delta \delta}{\delta_{C R}}=\frac{\Delta \delta}{\delta_{M A X}} \frac{\delta_{M A X}}{\delta_{C R}}=\Delta_{o} \frac{\delta_{M A X}}{\delta_{C R}}=\sqrt{2 Z} \kappa S L_{M A X}^{2} \geq D_{T H}
$$

Special analytical precautions, however, are needed when $\mathrm{D}<\mathrm{D}_{\mathrm{TH}}$ which can also be formulated as

$$
\begin{array}{llll}
Z & <Z_{T H} \quad \text { where } & Z_{T H}=\frac{1}{2}\left(\frac{D_{T H}}{\kappa S L_{M A X}^{2}}\right)^{2} \\
S L_{M A X} \sqrt{\kappa}<S L_{T H} & \text { where } & S L_{T H}=\frac{\left(4 D_{T H}^{2} / C\right)^{1 / M}}{U(1-p)} \\
\Delta S L \sqrt{\kappa}<\Delta S L_{T H}=\frac{\left(4 D_{T H}^{2} / C\right)^{1 / M}}{U} &
\end{array}
$$

We suggest that only extremely small alternating crack openings $(\Delta \delta=0)$ develop when $\mathrm{Z}<\mathrm{Z}_{\mathrm{TH}}\left(\mathrm{D}<\mathrm{D}_{\mathrm{TH}}\right)$. This means, 
we introduce $Z=0$ when $Z<Z_{T H}$ is predicted by Equation 24

The consequences of using Equation 31 in a fatigue analysis are that the results of a $\mathrm{SL}_{\mathrm{MAX}}$ versus $\mathrm{N}_{\mathrm{CAT}}$ analysis are truncated at $\mathrm{SL}_{\mathrm{MAX}}=\mathrm{SL}_{\mathrm{TH}}$ such that $\mathrm{N}_{\mathrm{CAT}}=$ $\infty$ are predicted for any $\mathrm{SL}_{\mathrm{MAX}}<\mathrm{SL}_{\mathrm{TH}}$.

It is emphasized that the hypothesis made is very preliminary. From examples subsequently presented in Section 5.2 it seems that threshold parameters $\mathrm{D}_{\mathrm{TH}} \approx$ 0.001 to 0.0001 are orders of magnitudes which might be expected in fatigue of wood. 


\section{Viscoelastic fatigue}

Lifetime of a viscoelastic material can be determined following a similar procedure as previously used in the analysis of the elastic fatigue phenomenon. Modifcations of the method, however, have to be introduced which consider creep and the influence of crack closure on this phenomenon. Power law creep is assumed with a special relaxation time $\tau$ which is discussed in further details in Chapter 5 . Number of cycles to failure initiation $\mathrm{N}_{\mathrm{S}}$ is ignored for the same reason as explained in Section 2.4: $\mathrm{N}_{\mathrm{S}}$ is in practice much smaller than total number of cycles $\mathrm{N}_{\text {CAT }}$ leading to catastrophic materials failure.

\subsection{Model}

We model the opening history by "generalizing" the history applying to the "elastic" Dugdale-Rice crack shown in Figure 4: A creeping Dugdale opening develops at max load. When load drops to minimum a "frozen" Rice opening profile is produced with crack openings kept from just before load dropped except in the area $s>s_{0}$ where they are reduced with up to $\Delta \delta$ at $s=1$. When load jumps to its maximum again a Dugdale opening profile is restored, and the history just explained repeats itself cycle after cycle. The concepts of the model can be studied in Figure 13.

Remark: A minor modification of the model is introduced in the subsequent section which considers that a frozen crack profiles cannot always be produced.

\section{Creep of model}

Two features are un-known in the opening history outlined: We do not know how creep develops and how big are the $\delta$-jumps associated with loads going from minimum to maximum. To solve these problems we will use the elastic-viscoelastic analogy expressed by Equation 1.

To do so we must first assure ourselves that the crack opening of an elastic duplicate can be thougth of which equals a Dugdale opening (with coherent stress $\sigma_{\mathrm{COH}}$ $=\sigma_{1}$ ) when load is maximum - and that a relaxing closed crack opening can be thought of (with relaxing coherent stresses $\left|\sigma_{\mathrm{COH}}\right|<\sigma_{1}$ ) when load is minimum. Exact duplicates are vital preconditions for using the elastic-viscoelastic analogy.

There are no problems in thinking of exact duplicates when load is at its maximum. However, when load is at its minimum it is not that obvious that such duplicates exist. This feature has been considered in a new crack closure theory developed by the author in ( 3 , Appendix B). The result is positive as indicated in 
Figures $10-12$ based on this theory. $\left(\sigma_{\mathrm{T}}\right.$ and $\sigma_{\mathrm{F}}$ are averaged coherent stresses for $\mathrm{s} \leq \mathrm{s}_{0}$ and for $\mathrm{s}>\mathrm{s}_{\mathrm{o}}$ respectively). The relaxation, however, is not unlimited. It is explained in (3) that there is a lower limit of $\delta / \delta_{\text {MAX }}=p^{2}$ on closure relaxation (load ratio $\mathrm{p}$ ).

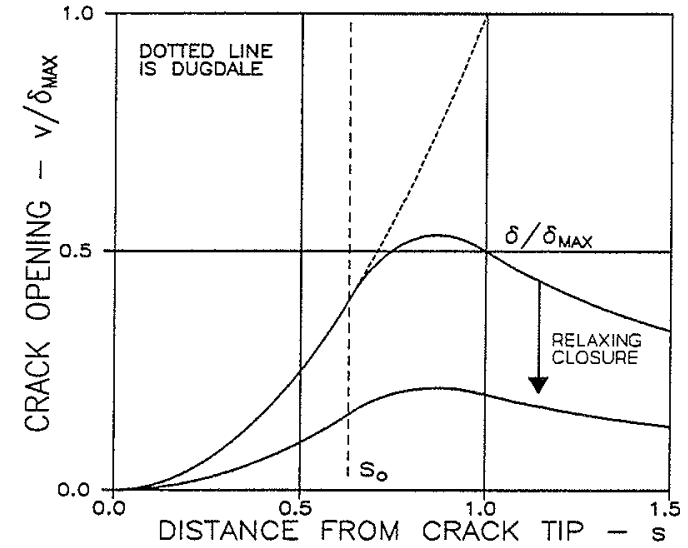

Figure 10. Relaxing closure when $p=0$. Illustrated $\sigma_{P} / \sigma_{l}=-1 \rightarrow-0.4$.

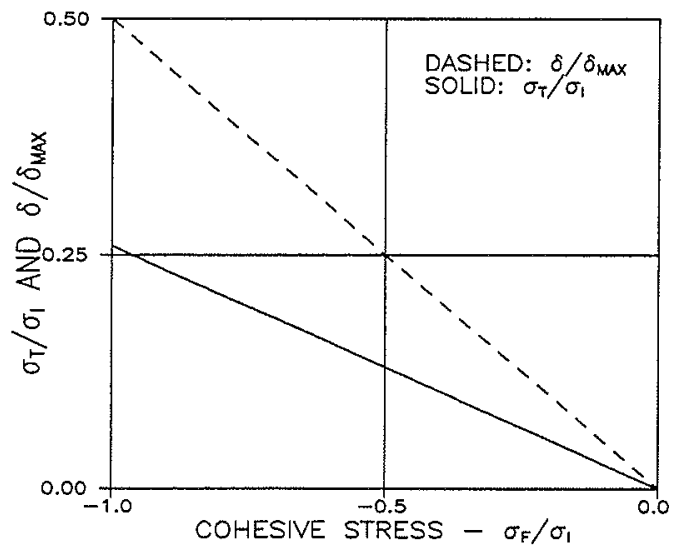

Figure 12. Relaxing closure as related to $\sigma_{F} / \sigma_{l}$ increasing from $-1 . p=0$.

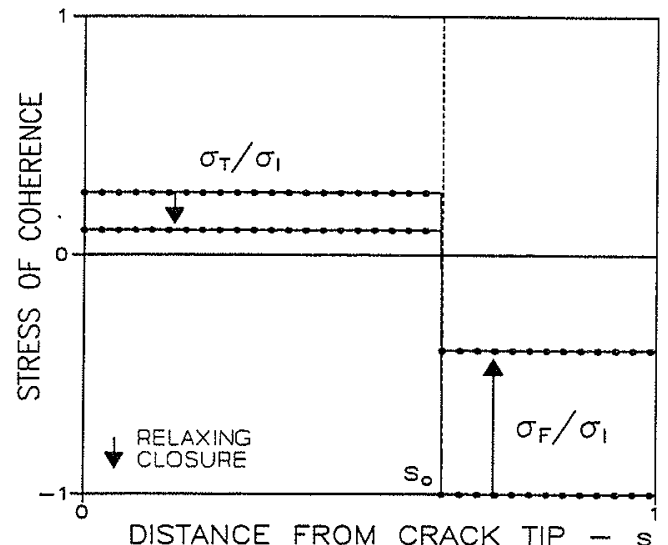

Figure 11. Relaxing closure when $p=0$. Illustrated $\sigma_{F} / \sigma_{l}=-1 \rightarrow-0.4$.

The missing quantitative information previously mentioned on creep and $\delta$-jumps can now be determined solving Equation 1 with boundary conditions explained by the model previously introduced. An example is shown in Figure 13 with free relaxation of the elastic crack. In the example illustrated in Figure 14 the elastic relaxation meets the lower limit of $\delta / \delta_{\mathrm{MAX}}=\mathrm{p}^{2}$, meaning that the boundary condition, "constant viscoelastic crack opening versus relaxing elastic crack opening" switches to "constant elastic crack opening versus creeping viscoelastic crack opening", (this feature explains the modification of the model indicated in the previous section). It is noticed that the lower limit of $\delta / \delta_{\mathrm{MAX}}=\mathrm{p}^{2}$ corresponds exactly to the crack front opening which would appear under a constant load level $S L=\mathrm{SL}_{\mathrm{MIN}}$, see Equation 9 for example.

It is convenient in the fatigue analysis of viscoelastic materials to introduce a crack closure creep function $\mathrm{C}_{\mathrm{CL}}$ defined as a continuous graph which envelopes the viscoelastic peaks found in the process of solving Equation 1, see Figure 13. 
And it is very adequate to express this function approximately as a time shifted original creep function, meaning $\mathrm{C}_{\mathrm{CL}}=\mathrm{C}(\mathrm{t} / \mathrm{h})$ with shift factor $\mathrm{h}$.

In the authors experience $\mathrm{h}$ can be determined, with sufficient accuracy, from calculated peak at the third cycle. A slightly less accurate way of determining $h$ is to consider the first cycle by elementary rheological rules and then modify the results by a computer analysis. The h-estimates such obtained are presented in Equation 32 applying for normalized frequencies $\left.\langle f\rangle=f^{*} \tau\right\rangle$ approximately 0.01 .

$$
\begin{aligned}
& C_{C L}(t) \approx 1+\left(\frac{t}{h \tau}\right)^{b} \text { with } h \approx 0.8+0.2 \mu \\
& \text { where } \mu=\left[\beta^{b}+\left(\Delta^{\prime}-\Delta_{o}\right)\langle f\rangle^{b}\right]^{-1 / b} \text { with } \Delta^{\prime} \approx \frac{\left.1-\beta^{b}+\Delta_{o}<f\right\rangle^{b}}{\langle f\rangle^{b}+(1-\beta)^{b}}
\end{aligned}
$$

Remark: Expression 32 applies as long as $\Delta^{\prime} \leq 1-\mathrm{p}^{2}$ is predicted (free elastic relaxation). When $\Delta^{\prime}>1-\mathrm{p}^{2}$ we may put $\mathrm{h}=1$, meaning that the closure creep function is approximated by the original creep function. It is noticed from Figure 14 that closure creep increases towards the original creep function when elastic relaxation is restrained. To introduce $h=1$ is safe with respect to lifetime prediction. Equation 32 can be used in most practice - as reflected in any example subsequently considered.

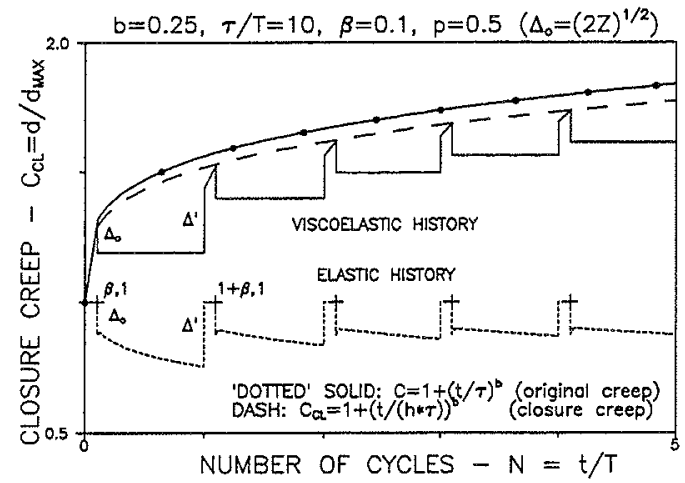

Figure 13. Associated elastic and viscoelastic crack openings. Rice $Z=(1-p)^{4} / 8$.

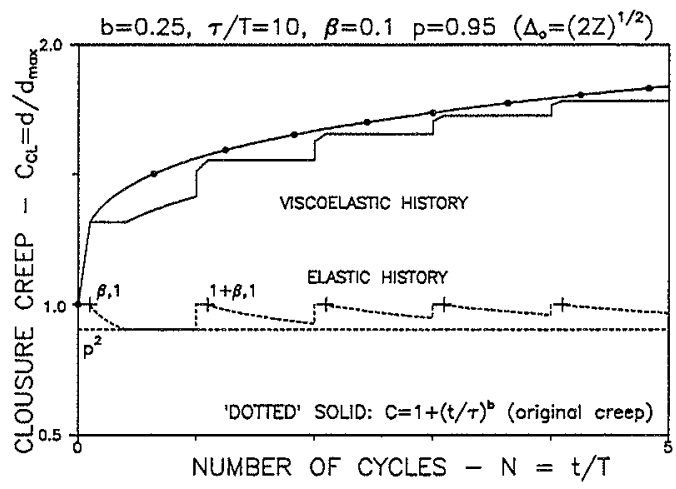

Figure 14. Associated elastic and viscoelastic crack openings. Rice $Z=(1-p)^{4} / 8$.

\subsection{Damage rate}

We can now determine damage rate in viscoelastic materials applying exactly the same procedure as used when elastic materials are considered, see Section 2.4 and Chapter 3. In energy calculations, however, we have to modified deformations according to the closure creep function established in the previous section. 
The time, $\Omega$, it takes a crack to propagate a distance, $R_{M A X}$, in a viscoelastic material is determined by energy considerations just as in Section 3.1 looking at elastic fatigue. Analytically the energy dissipation at the crack front can with sufficient accuracy be expressed as follows

$$
\Gamma_{C R}=\sigma_{l} \delta_{M A X}\left[C_{C L}\left(\frac{\Omega}{q}\right)+\frac{\Delta \delta}{\delta_{M A X}}\left(1-s_{o}\right) \frac{\Omega}{T}\right]=\sigma_{l} \delta_{M A X}\left[C_{C L}\left(\frac{\Omega}{q}\right)+Z \frac{\Omega}{T}\right]
$$

where the former term(s) express energy dissipation developed by the crack opening in periods of time with max load including the time dependent part of opening jumps build up in periods of time with min load. The latter term(s) in Equation 33 represent dissipation due to the elastic parts of opening jumps.

The factor $q$ in Equation 33 considers that the position considered which is penetrated by the crack does not experience maximum crack opening at once (in which case $q=1$ ). For a parabolically increasing opening history in a Power law viscoelastic material $\mathrm{q}$ is developed in (7) as follows,

$$
q=\left[\frac{(1+b)(2+b)}{2}\right]^{1 / b}
$$

Equation 33 can also be written as presented in Equation 35 introducing the closure creep expression from Equation 32, critical strain energy release rate from Equation 9, and normalized frequency $\langle\mathrm{f}\rangle=\tau * \mathrm{f}=\tau / \mathrm{T}$.

$$
\begin{aligned}
& \frac{1}{\kappa S L_{M A X}^{2}}=C_{C L}\left(\frac{\Omega}{q}\right)+Z \frac{\Omega}{T}=1+\left(\frac{\Omega / T}{q h<f>}\right)^{b}+Z \frac{\Omega}{T} \\
& \frac{1-\kappa S L_{M A X}^{2}}{\kappa S L_{M A X}^{2}}=\left(\frac{1}{q h<f>}\right)^{b}\left(\frac{\Omega}{T}\right)^{b}+Z \frac{\Omega}{T}
\end{aligned}
$$

$\Omega$ can be eliminated in Equation 35 introducing damage velocity, $\mathrm{d} / \mathrm{dN}$ according to Equation 17 which can also be written

$$
\frac{\Omega}{T}=\Phi F L^{2} \frac{d N}{d \kappa} \quad \text { with } \quad \Phi=\frac{\pi^{2}}{8} \kappa S L_{M A X}^{2}
$$

Now Equation 35 can be written as follows relating damage velocity to damage ratio $\kappa$, 


$$
Y=A_{1} X^{b}+A_{2} X-A_{3}=0 \quad \text { with } \quad X=F L^{2} \frac{d N}{d \kappa}
$$

where $A 1, A 2$, and $A 3$ are parameters to be calculated from Equation 38 with $\mathrm{Z}$ expressed by Equations 24, 26, 30, and 31 .

$$
\begin{aligned}
& A_{1}=\left(\frac{\Phi}{q h<f>}\right)^{b} \text { with } \Phi=\frac{\pi^{2}}{8} \kappa S L_{M A X}^{2} \text { and } A_{3}=\frac{1-\kappa S L_{M A X}^{2}}{\kappa S L_{M A X}^{2}} \\
& A_{2}=\Phi Z
\end{aligned}
$$

\subsection{Lifetime and residual strength}

At a fixed damage ratio $\kappa$ Equation 37 can be solved easily applying the Newtons iteration principle,

$$
X_{N E W}=X-\frac{Y}{d Y / d X}=\frac{A_{1} X^{b}+A_{2} X-A_{3}}{b A_{1} X^{b-1}+A_{2}}
$$

\section{Algorithm}

Lifetime is then calculated by numerical integration as shown in the algorithm presented in Table 1 with the following first estimate on initial damage rate and $\kappa$-steps $\Delta \kappa$ suggested in (1). Another first estimate migth be introduced. The one applied, however, works well. The accuracy of calculations migth be increased with smaller $\Delta \kappa$. A number of tests, however, show that $\Delta \kappa$ as applied is adequate for most analysis.

$$
X_{0} \approx\left\langle f>\frac{\left(S L_{M A X}^{-2}-1\right)^{1 / b}}{S L_{M A X}^{2}} ; \Delta \kappa=\frac{1}{\rho}\left(\frac{1}{S L_{M A X}^{2}}-1\right) \text { with } \rho>1000\right.
$$

The integration starts at $\kappa=1$ and stops at $\kappa=\kappa_{C R}=S_{M A X}{ }^{-2}$ where the damage rate becomes infinitely high.

Materials strength still remaining after a certain number of load cycles $\mathrm{N}$ is predicted by the residual strength fraction $S_{R}$ just as in Section 3.3 (or Equation 10) considering elastic fatigue. The result is presented in Equation 41 which predicts $S_{R}=1$ at $t=0$ and $S_{R}=S L_{M A X}$ at $N=N_{C A T}$. 


$$
S_{R}=\frac{\sigma_{C R}(\kappa)}{\sigma_{C R}}=\frac{1}{\sqrt{\kappa(N)}}
$$

TABLE 1. Lifetime and residual strength of wood: Harmonic load variation

GIVEN: Material: $F L, \tau, b, C, M, p_{C R}, D_{T H}$, and $q(34)$

LOAD: $S L_{M A X}, p, f, \beta$

STEP: $\quad \Delta \kappa \approx\left(1 / S L_{M A X}^{2}-1\right) / 1000$

START: $\kappa, t, N=1,0,0$

- Calculate: $U(26), Z(24,30,31), h(32+$ remark $),\left(A_{1}, A_{2}, A_{3}\right)(38)$

If $\kappa=1: X=f \tau \frac{\left(S L_{M A X}^{-2}-1\right)^{1 / b}}{S L_{M A X}^{2}} \quad$ (first estimate)

- $\quad Y=A_{1} X^{b}+A_{2} X-A_{3} \quad ; \quad d Y / d X=b A_{1} X^{b-1}+A_{2}$

$X_{N E W}=X-\frac{Y}{d Y / d X} \quad$ (Newton)

If $\left|\frac{X_{N E W}}{X}-1\right|<0.00001$ go to

$X=X_{N E W}$

goto

- $X=X_{N E W}$

$\Delta N=\frac{X \Delta \kappa}{F L^{2}} \quad ; \quad \Delta t=\frac{\Delta N}{f}$

$\kappa=\kappa+\Delta \kappa ; \quad t=t+\Delta t ; \quad N=N+\Delta N$

$S_{R}=1 / \sqrt{\kappa}$

WRITE RESIDUAL STRENGTH: $t, N, S_{R}$

If $\mathrm{K}>\mathrm{K}_{C R}=\frac{1}{S L_{M A X}^{2}}$ goto

goto

$t_{C A T}=t, N_{C A T}=N$

WRITE LIFETIME: $t_{C A T}, N_{C A T}$

The elastic fatigue results previously presented are predicted by the algorithm presented in Table 1 introducing a normalized frequency $\langle\mathrm{f}\rangle \rightarrow \infty$, meaning that $\tau$ and/or $\mathrm{f} \rightarrow \infty$. Static lifetime (duration of load) is predicted introducing a load ratio of $\mathrm{p}=1$. This feature is explained in further details in Section 4.4. 


\section{Endurance limit}

An example is constructed in Figures 15 and 16 to illustrate how the algorithm just presented handles the question of a postulated endurance limit defined by a threshold parameter of $\mathrm{D}_{\mathrm{TH}}=0.0005$ (endurance limit $\mathrm{SL}_{\mathrm{TH}} \approx 0.4$ ). Other parameters used in the example are: $(\mathrm{FL}, \mathrm{b}, \tau)=(0.4,0.25,1$ day $),\left(\mathrm{C}, \mathrm{M}, \mathrm{p}_{\mathrm{CR}}\right)=(3$, 9, -0.75), $(p, B)=(0,0.5)$, and $f=1 \mathrm{~Hz}$.

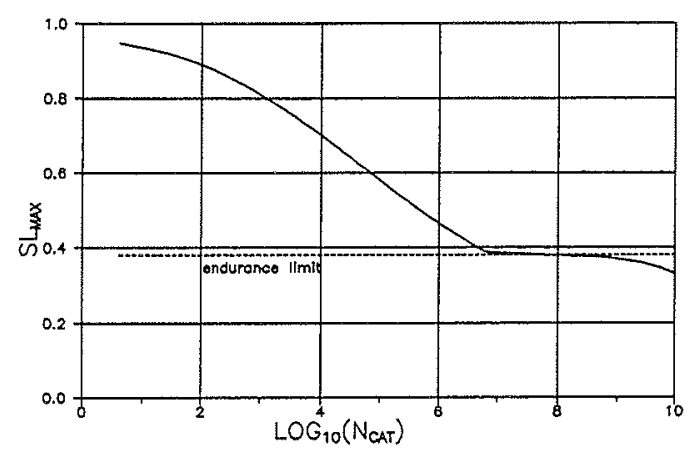

Figure 15. Number of cycles to failure predicted with endurance limit $S L_{T H} \approx 0.4$.

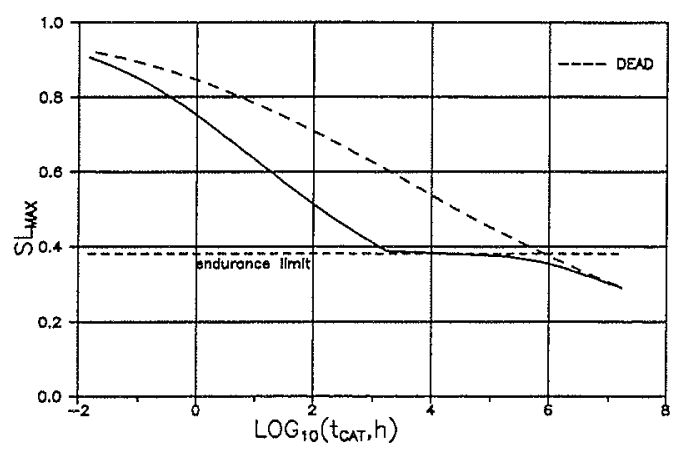

Figure 16. Time to failure predicted with endurance limit $S L_{T H} \approx 0.4$.

Remark: It is noted that materials with Power-law creep will always fail irrespective of load level. This is a consequence of this creep function not having a finite value as time proceeds to long times. Other materials with creep functions having final values of $\mathrm{C}(\infty)$ will have minimum thresholds of $\mathrm{SL}_{\mathrm{TH}}=(1 / \mathrm{C}(\infty))^{1 / 2}$ below which no fatigue failure will ever occur (14).

\section{Generalized load history}

Lifetime and residual strength of wood subjected to load histories defined in Figure 1 are considered immediately by the algorithm presented in Table 1. Other load histories, however, can easily be considered. This feature is considered in more details in subsequent Section 6.2 and Appendix $\mathrm{A}$ at the end of the paper where a generalized algorithm is presented.

\subsection{Static load (dead load)}

Deadload lifetime and residual strength are obtained by the algorithm in Table 1 introducing a load ratio of $p=1$. Analytical solutions, however, can be obtained directly from Equation 37 which relates damage and time as follows with $p=1$ and normalized time $\langle t\rangle=t / \tau$. 


$$
\begin{aligned}
& \frac{d \kappa}{d t}=\frac{(\pi F L)^{2}}{8 q \tau} \frac{\kappa S L^{2}}{\left[\left(\kappa S L^{2}\right)^{-1}-1\right]^{1 / b}} \Rightarrow \\
& <t>F L^{2}=\frac{8 q}{\pi^{2} S L^{2}} \int_{\alpha}^{\beta} \frac{x^{1 / b}}{1+x} d x \quad \text { with }\left(\begin{array}{l}
\beta=1 / S L^{2}-1 \\
\alpha=1 /\left(\kappa S L^{2}\right)-1
\end{array}\right.
\end{aligned}
$$

Lifetime: Time to catastrophic failure is determined from this expression introducing a critical damage ratio of $\kappa_{\mathrm{CR}}=1 / \mathrm{SL}^{2}$, meaning $\alpha=0$. Closed formed lifetime solutions to Equation 42 are presented in Equation 43 reproduced from (7).

$$
\begin{array}{lr}
<t_{C A T}>F L^{2}= & \text { with } \mu=\frac{1}{S L^{2}}-1 \\
\frac{3.1}{S L^{2}}\left[\frac{\mu^{3}}{3}-\frac{\mu^{2}}{2}+\mu-\log (\mu+1)\right] & b=\frac{1}{3} \\
\frac{3.2}{S L^{2}}\left[\frac{\mu^{4}}{4}-\frac{\mu^{3}}{3}+\frac{\mu^{2}}{2}-\mu+\log (\mu+1)\right] & b=\frac{1}{4} \\
\frac{3.2}{S L^{2}}\left[\frac{\mu^{5}}{5}-\frac{\mu^{4}}{4}+\frac{\mu^{3}}{3}-\frac{\mu^{2}}{2}+\mu-\log (\mu+1)\right] & b=\frac{1}{5}
\end{array}
$$

Residual strength: Residual strength (strength fraction $S_{R}$ ) remaining during the fatigue process is easily determined by Equation 42 introducing $\kappa=1 / S_{R}{ }^{2}$. This means that residual strength and time are related simply by introducing a lower limit of integration $\alpha=\left(S_{R} / S L\right)^{2}-1$. Residual strength starts at $S_{R}=1$ and ends at $\mathrm{S}_{\mathrm{R}}=\mathrm{SL}$ where $\alpha=0$. We get

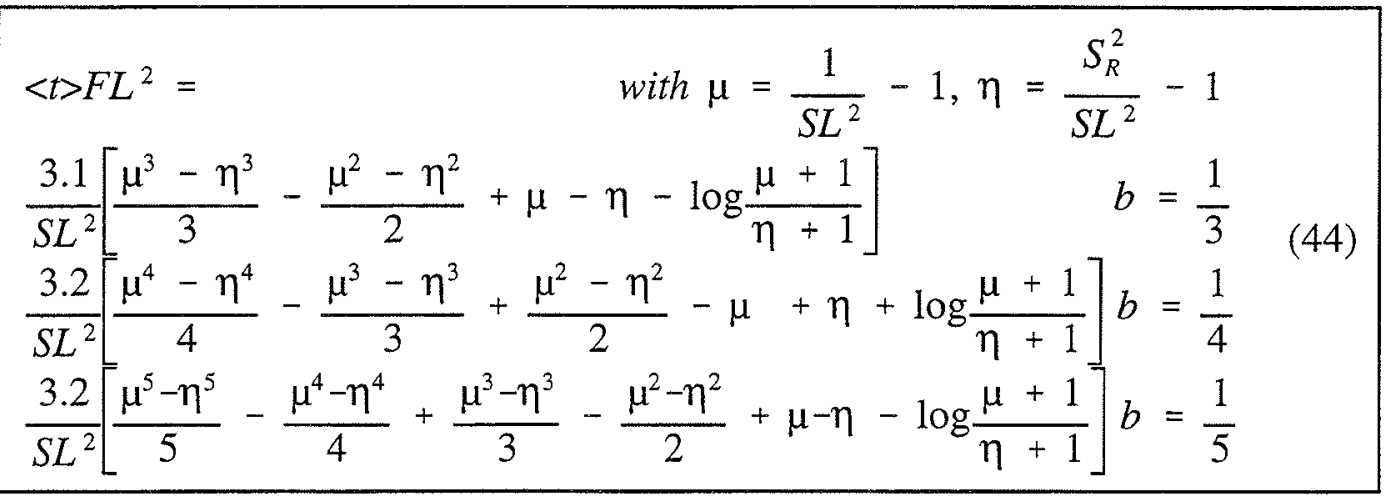

Illustrative examples on predictions of static lifetime and residual strength are presented in Figures 17 and 18. 


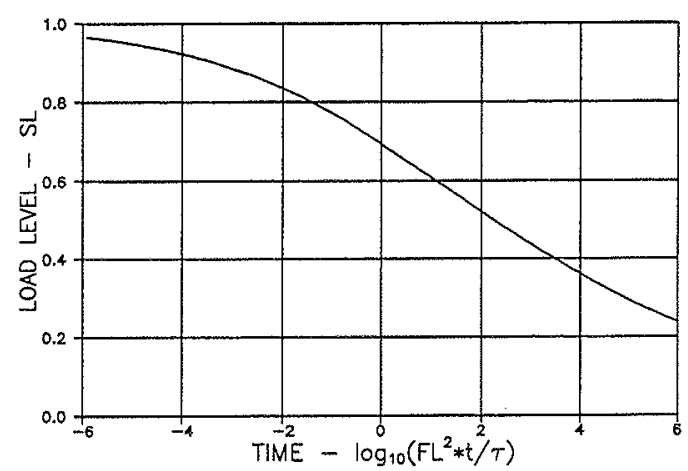

Figure 17. Lifetime of wood with creep power $b=0.25$.

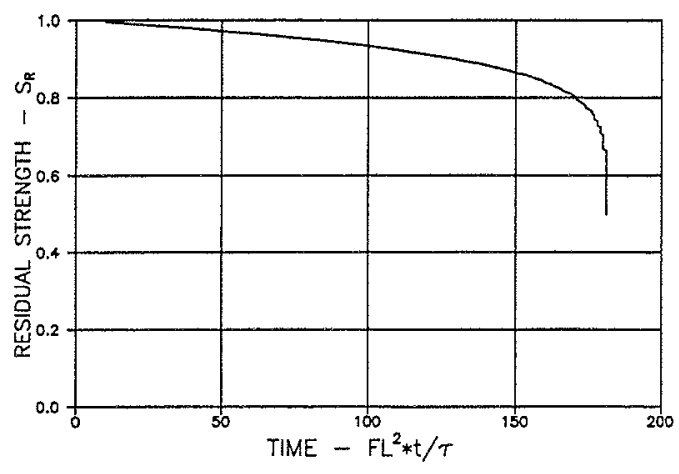

Figure 18. Residual strength of wood with creep power $b=0.25$. Load is $S L=0.5$.

Remark: It has been shown in (13) that the theory developed for static loads can be applied also for moderately varying loads when rate of loading does not violate Equation 45. If it does, crack closure is encountered.

$$
\frac{d S L}{d t} \geq-\frac{S L}{2 \tau\left(1 /\left(\kappa S L^{2}\right)-1\right)^{1 / b}}
$$




\section{Theory and experiments}

Experimental results are compared in this chapter with theoretical predictions made by the algorithm presented in Section 4.3. The procedure of comparing is arranged such that materials data not known are introduced by calibration. Calibrated values, however, must show consistency with similar data deduced in other ways, experimentally or theoretically. Such data, named "OM-estimates" (orders of magnitudes) are presented in the subsequent section. The concept of load level representation of experimental data is also considered.

\subsection{Preparation of algorithm}

\section{Strength level, FL}

Strength levels of damaged materials can be estimated by the following theoretically based expression presented in (10). A characteristic micro structural dimension of the material considered is denoted by $\mathrm{d}$. Crack length is denoted by $1_{\mathrm{o}}$. When wood especially is considered we may estimate $d \approx$ (fibre length*fibre

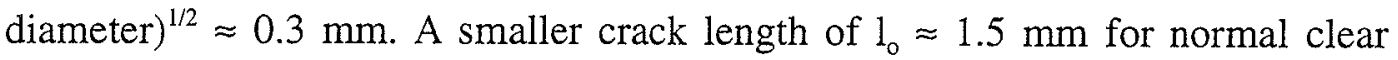
wood has been estimated from (36). Generally we estimate normal clear wood to have $0.5>\mathrm{FL}>0.2-0.3$ and structural wood to have $\mathrm{FL}<0.2-0.3$. The term, "clear", should not be taken too rigorously. Badly treated clear wood may easily exhibit a "structural" wood strength level.

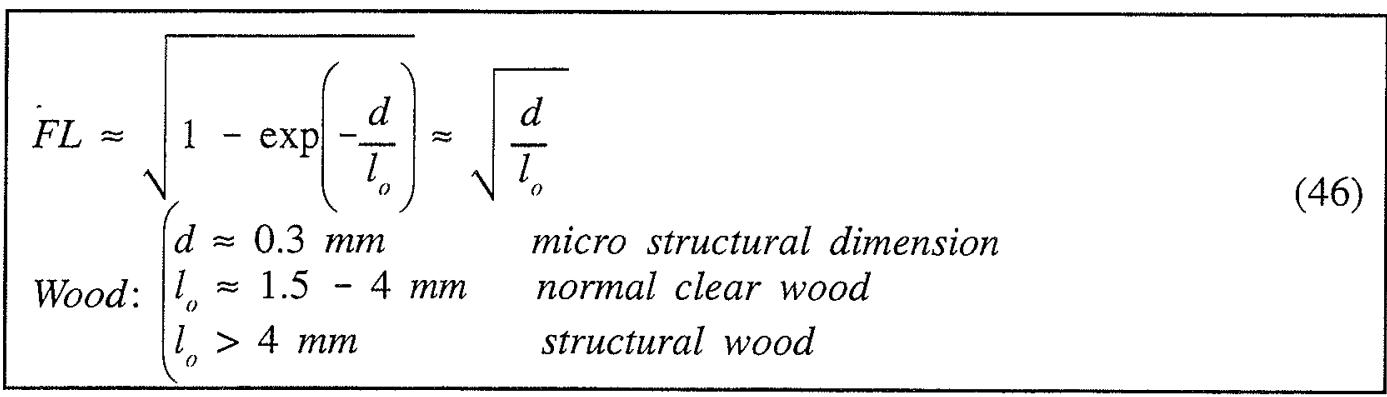

\section{Load level, SL}

Load levels are based on reference strengths $\sigma_{\mathrm{CR}}$ determined as follows: Strength at load ratios $\mathrm{p} \geq 0$ is strength measured traditionally (compression, tension, bending). Strength at load ratios $\mathrm{p}<0$ is $\sigma_{\mathrm{MAX}}$ with failure appearing after a few (23 ) fast cycles with load ratio $p$ used in lifetime experiment. The rationale behind this suggestion is that similar mechanisms initiate both tension failure and compression failure $(1,7)$ although final failure textures may look completely different. If special $\sigma_{\mathrm{CR}}$-tests are not made, $\sigma_{\mathrm{CR}}$ is estimated from extrapolating backwards to a few cycles on the experimentally obtained lifetime graph. 
Strength and lifetime data are very sctered in fatigue experiments on wood. The most common way of handling this problem is to present data by average values of strength and lifetime. Unless otherwise indicated experimental data presented in this paper are based on this concept of data representation. A more rational way of treating experimental data has been introduced into fatigue research by Borg Madsen in (37). The Borg Madsen's method (MB) of data representation, discussed and evaluated by the present author in $(7,11)$, respects the individuality of any member being tested without loosing consistency with the common way of data representation. Experimental data subsequently referred to from (38) are treated according to the BM-method.

\section{Damage rate power and damage rate constant}

The damage rate power $M$ can be determined as follows from experimental lifetime obtained at higher load frequencies (where creep effects are relatively small). The data are presented in a $\log _{10}\left(\mathrm{~N}_{\mathrm{CAT}}\right)-\mathrm{SL}_{\mathrm{MAX}}$ graph. From this graph $\mathrm{M}$ is derived by Equation 47 developed in (2).

$$
\left.M \approx-10\left[1+2 \log _{10}(B)\right] \text { with } B=-\frac{d\left[S L_{M A X}\right]}{d\left[\log _{10}\left(N_{C A T}\right)\right]}\right]_{S L_{M A X}} \approx 0.6
$$

Damage rate constant $\mathrm{C}$ can be deduced very easily from a similar data representation utilizing that this parameter is responsible for parallel shifting only. In this way $\mathrm{M}=9$ and $\mathrm{C}=3$ (at $\mathrm{FL} \approx 0.4$ ) were deduced in (1) from lifetime data reported in (39) from fatigue tests on Pine heartwood with $(\mathrm{p}, \mathrm{f})=(-1,50 \mathrm{~Hz})$.

In this paper $(M, C) \approx(9,3)$ are declared OM-estimates for damage power and damage rate constant in wood. We re-call $\mathrm{M}=8.5$ previously mentioned in this paper which was deduced from experiments reported in (33).

\section{Critical load ratio and threshold factor}

A critical load ratio of $\mathrm{p}_{\mathrm{CR}} \approx-0.5$ has been deduced in (1) from the data on Pine heartwood (39) previously used to deduce $M$ and $C$. The quantity of $p_{C R} \approx-0.5$ is declared as an OM-estimate for critical load ratio in this study. The efficiency factors $U=(1+p) / 2$ for $p \geq 0$ theoretically determined by the present author and $\mathrm{U}=0.5+0.4 \mathrm{p}$ empirically suggested by Elber for $\mathrm{p}>-0.1$ are described very well by Equation 26 for any $\mathrm{p}_{\mathrm{CR}}<0$.

A threshold parameter of $D_{T H}=0$ is considered as an OM-estimate in this study. As previously indicated, very little is known in the area of thresholds in fatigue. 
For illustrative purposes, however, estimates of $\mathrm{D}_{\mathrm{TH}}=0.0001$ and 0.001 are introduced in two examples presented in the subsequent Section 5.2.

\section{Creep}

In the present context creep refers to a combined opening mode and sliding mode viscoelasticity in the vicinity of a crack. For two reasons we can only estimate the relaxation time for this process very roughly. We know relatively little on anisotropic creep of bulk wood (40, review) - and we know almost nothing on microstructural creep in wood. The orders of magnitudes on $\tau$ presented in Equation 48 are estimates (see 1,7) based on what is known (e.g. 41,42) on bulk creep versus loading modes. A factor of $10^{-1 \pm 1}$ is included which considers the microstructural aspects that cracks propagate in areas of minimum resistance (the softer areas), and that creep locally is higher at the higher stressed crack front areas than it is in the lower stressed bulk material.

Equation 48 relates $\tau$ to relaxation time $\tau_{B, R E F}$ measured in bending of bulk wood at a reference equilibrium moisture content of $\mathrm{u}=\mathrm{u}_{\mathrm{REF}}$ (at reference temperature $\mathrm{T}_{\mathrm{REF}} \approx 20^{\circ} \mathrm{C}$ ). A $\tau_{\mathrm{B}, \mathrm{REF}}$ of $\approx 10^{4}$ days at $\mathrm{u}_{\mathrm{REF}} \approx 10 \%-12 \%$ might be estimated if information on bulk creep is insufficient. Unfortunately, this is almost always the case when fatigue results are reported in the literature. Other equilibrium moisture conditions than $\mathrm{u} \approx 10 \%-12 \%$ are considered by the factor $\mathrm{d}_{U}$ presented in $\mathrm{E}$ quation 48 .

$\log _{10} \tau($ days $) \approx \log _{10} \tau_{B, R E F}($ days $)-3.5 \pm 1+d$ with
$d_{U} \approx \frac{u_{R E F} \%-u \%}{10} ;$ if $u>30 \%$, then $u=30 \%$

Tension $\perp$ to grain has the lower $\tau$ and $b \approx 1 / 3$

Compression \| to grain has the lover $\tau$ and $b \approx 1 / 4$

Other loading modes have the higher $\tau$ and $b \approx 1 / 4$

The moisture factor $d_{U}$ is an average and might therefor easily differ from factors deduced from tests on specific types of wood. For example, Hoffmeyer suggested a factor equivalent to $\mathrm{d}_{\mathrm{U}} \approx\left(\mathrm{u}_{\mathrm{REF}} \%-\mathrm{u} \%\right) / 5$ from experiments on red spruce (43). Dynamic moisture changes influence relaxation time dramatically - possibly by factors less than 0.1 . The creep power, $b$, can be considered independent of moisture content. A theory has recently been presented in $(44,45)$ by which harmonically (such as yearly) varying humidity variations can be considered as fictitious equilibrium conditions. It is obvious how this feature increases the potentials in practice of the theory presented. It has been indicated in $(44,45)$ that the so-called phenomenon of mechano-sorptive creep is not very 
important in practice. Mechano-sorptive creep is, like in concrete, structural consolidation which is normally massaged away by normal handling of material long time before it takes a load carrying role.

It has been indicated that static lifetime is predicted fairly well with relaxation time estimated by Equation 48. Equation 48 is therefor declared as OM-estimates for relaxation time also in fatigue analysis.

Remarks: Temperature variations influence creep in a similar way as moisture content. A temperature factor equivalent to $\mathrm{d}_{\mathrm{T}} \approx\left(\mathrm{T}_{\mathrm{REF}}{ }^{\circ} \mathrm{C}-\mathrm{T}^{\circ} \mathrm{C}\right) / 15$ in Equation 48 has been suggested in (1).

\begin{tabular}{|c|c|c|c|c|c|}
\hline Figure & Material & Load & $\begin{array}{l}\text { Mat-prop: FL, } b, \tau \text { (days) } \\
\text { Reference strength } \sigma_{\mathrm{CR}} \text { or } \mathrm{S}\end{array}$ & \begin{tabular}{|c|} 
Fatigue-prop \\
$\mathbf{C}, \mathbf{M}, \mathbf{p}_{\mathrm{CR}}, \mathbf{D}_{\mathrm{TH}}$
\end{tabular} & Exp-reference \\
\hline $19-21$ & Spruce & $\begin{array}{l}\text { compression } \| \text { grain }(\mathrm{sq}) \\
\mathrm{p}=0, \mathrm{f}=10^{-6}-0.1 \mathrm{~Hz}\end{array}$ & $\begin{array}{c}0.4,0.25,1 \\
\text { Compress-strength } \sigma_{\mathrm{CR}}=37 \mathrm{MPa}\end{array}$ & 3,9, neg, 0 & Bach (46) \\
\hline $22-24$ & $\begin{array}{c}\text { Doug-Fir defected } \\
\text { || grain }\end{array}$ & $\begin{array}{l}\text { tension } 1 \text { grain }(\mathrm{sq}) \\
\mathrm{p}=0, \mathrm{f}=10^{-2}, 10^{-4} \mathrm{~Hz}\end{array}$ & $\begin{array}{c}0.2,1 / 3,0.5 \\
\text { Tens-strength } \sigma_{\mathrm{CR}}=2.35 \mathrm{MPa}^{*} \text { ) }\end{array}$ & 3,9, neg, 0 & $\begin{array}{l}\text { Nielsen \& Madsen } \\
\text { (38) }\end{array}$ \\
\hline $25-26$ & $\begin{array}{c}\text { Spruce Glu-lam } \\
\mathrm{u}=20 \%\end{array}$ & $\begin{array}{l}\text { bending with } p=0(\mathrm{sq}) \\
\mathrm{f}=2^{*} 10^{-5}, 0.05 \mathrm{~Hz}\end{array}$ & $\begin{array}{l}0.4,0.25,1 \\
\text { SL given by authors }\end{array}$ & 3,9, neg, 0 & $\begin{array}{l}\text { Marstrand \& Kri- } \\
\text { stensen (47) }\end{array}$ \\
\hline 27 & Pine-heartwood & $\begin{array}{l}\text { rotational bending } \\
\mathrm{p}=-1,50 \mathrm{~Hz}\end{array}$ & $\begin{array}{c}0.4,0.25,1 \\
\text { Estim } \sigma_{\mathrm{CR}}=116 \mathrm{MPa}(=\text { bend-str })\end{array}$ & $3,9,-0.6, .001$ & $\begin{array}{l}\text { Kraemer } \\
\quad(39)\end{array}$ \\
\hline 28 & $\begin{array}{l}\text { Particle- and } \\
\text { Hardboards }\end{array}$ & $\begin{array}{c}\text { tension \& interlam-shear } \\
p, f=0.1,15 \mathrm{~Hz}\end{array}$ & $\begin{array}{l}0.4,0.25,1 \\
\text { SL given by author }\end{array}$ & 3,9, neg, 0 & $\begin{array}{l}\text { McNatt } \\
(48,49)\end{array}$ \\
\hline 29 & \multirow{2}{*}{ Khaya 4-Ply } & $\begin{array}{l}\text { bending (s) with } \\
\mathrm{p}, \mathrm{f}=0.1,15 \mathrm{~Hz}\end{array}$ & \multirow{2}{*}{$\begin{array}{c}0.4,0.25,10 \\
\text { Estim } \sigma_{\mathrm{CR}}=95 \mathrm{MPa}(=\text { bending } \\
\text { strength })\end{array}$} & \multirow{2}{*}{$3,15,-0.75,0$} & \multirow[b]{2}{*}{$\begin{array}{l}\text { Ansell \& Tsai } \\
\quad(50)\end{array}$} \\
\hline 30 & & $\begin{array}{l}\text { reversed bending with } \\
p, f=-1,10 \mathrm{~Hz}\end{array}$ & & & \\
\hline 31 & $\begin{array}{l}\text { Doug-Fir fin- } \\
\text { ger joints }\end{array}$ & $\begin{array}{l}\text { tension } \| \text { grain } \\
\mathrm{p}, \mathrm{f}=0.1,15 \mathrm{~Hz}\end{array}$ & $\begin{array}{c}0.4,0.25,1 \\
\text { SL given by author }(51)\end{array}$ & 3,9, neg, .0001 & $\begin{array}{l}\text { Bohannan et al } \\
\text { (52) \& McNatt (51) }\end{array}$ \\
\hline 32 & $\begin{aligned} \text { Spruce } \\
\mathrm{u}=12 \& 18 \%\end{aligned}$ & $\begin{array}{c}\text { compression } \| \text { grain }(\mathrm{sq}) \\
\mathrm{p}=0, \mathrm{f}=0.01-10 \mathrm{~Hz}\end{array}$ & $\begin{array}{c}0.4,0.25,0.2(12 \%)-0.03(18 \%) \\
\mathrm{SL}=0.80 \text { given by authors }\end{array}$ & 3,12, neg, 0 & $\begin{array}{c}\text { Clorius, Pedersen et } \\
\text { al (53) }\end{array}$ \\
\hline
\end{tabular}

Table 2. Fatigue tests: Loading, material properties and fatigue parameters applied. Type of loading is sinusoidal except when square wave loading (with $\beta=0.5$ ) is indicated with (sq). Unless otherwise indicated clear wood with a moisture content of $u \approx 12 \%$ applies. Critical load ratio $p_{C R}=$ neg means arbitrarily negative. $\left.{ }^{*}\right) S L=0.7$ and 0.8 relative to $2.35 \mathrm{MPa}$, data treated by BM-method, see Section 5.1.

\subsection{Experiments versus theory}

The results of comparing experimental lifetime data with theoretically predicted lifetime are presented in this section. Experiments considered are identified in Table 2 together with material properties and fatigue parameters used theoretically. The theoretical status of experiments with sinus varying load and square wave varying load are considered approximately equal. Graphical representations of results are presented in figures indicated by the former column of Table 2. Experi- 
mental data are indicated by dots - theoretical data with solid and dashed lines. Individual comments on experiments or theory applied are appropriate to some of the examples presented in Table 2. They are as follows:

Figures 19 and 20: Another way of illustrating the frequency dependency of fatigue lifetime of spruce subjected to compressive load, is shown in Figure 21. This figure clearly confirms the statement that fatigue of wood is very much a function of load frequency.

Figures 23 and 24: The experiments on artificially defected Douglas-Fir were made as outlined in Figure 22 on specimens of size $140 \mathrm{~mm}$ perpendicular to grain $=$ load direction. Cross-section is $17 * 40 \mathrm{~mm}$. A $10 \mathrm{~mm}$ parallel to grain crack is cut through the specimen in the centre of the $40 * 140 \mathrm{~mm}$ face. A strength level of $\mathrm{FL}=0.3$ is introduced in analysis for this specimen. The artificial damage declassify the wood considered to wood of medium quality. A creep power of $b=1 / 3$ considers that load acts perpendicular to grain.

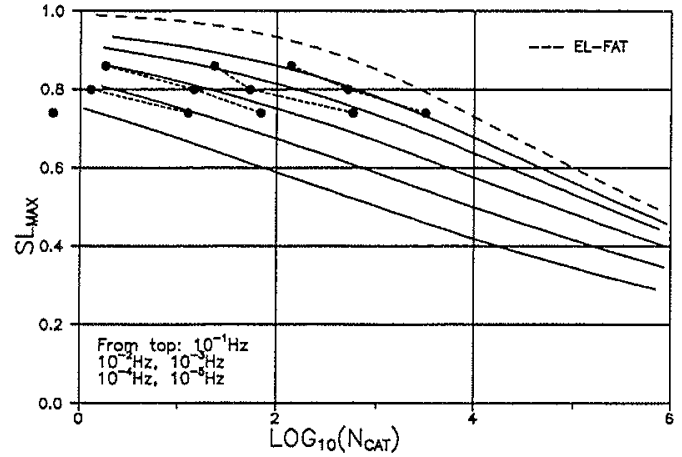

Figure 19. Fatigue of spruce compressed parallel to grain with $p=0$. Elastic fatigue indicated is predicted lifetime at very high frequency.

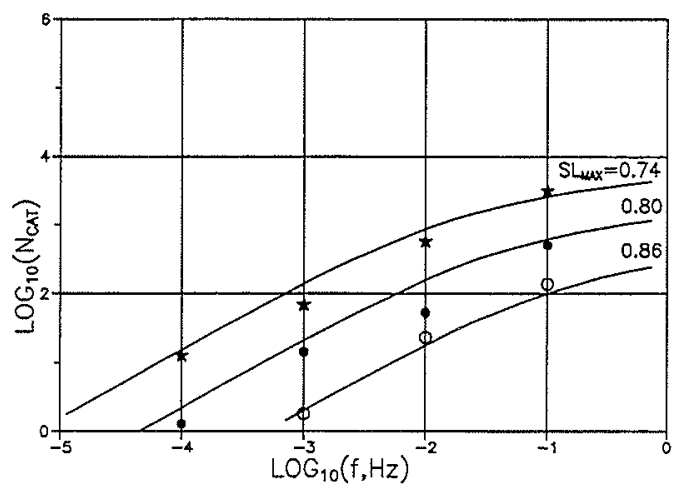

Figure 21. Fatigue of spruce in (46) compressed parallel to grain with $p=0$.

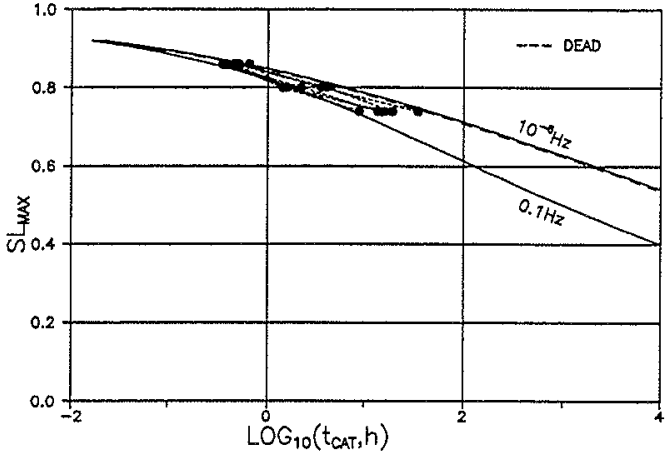

Figure 20. Fatigue of spruce compressed parallel to grain with $p=0$. Experimental, predicted $10^{-6} \mathrm{~Hz}$, and predicted deadload lifetime coincide.

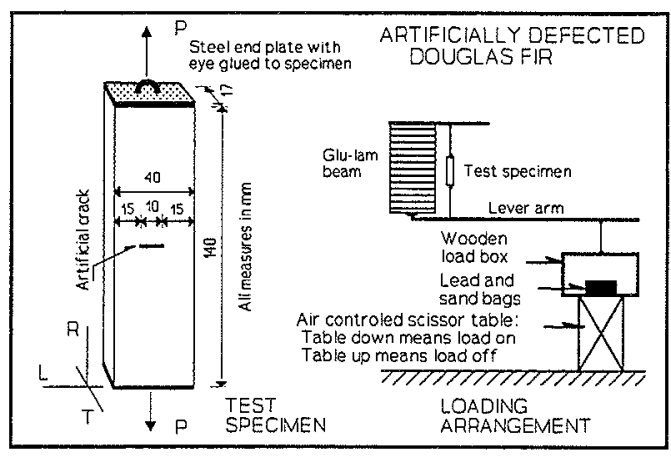

Figure 22. Test setup in fatigue experiments reported in (38). 


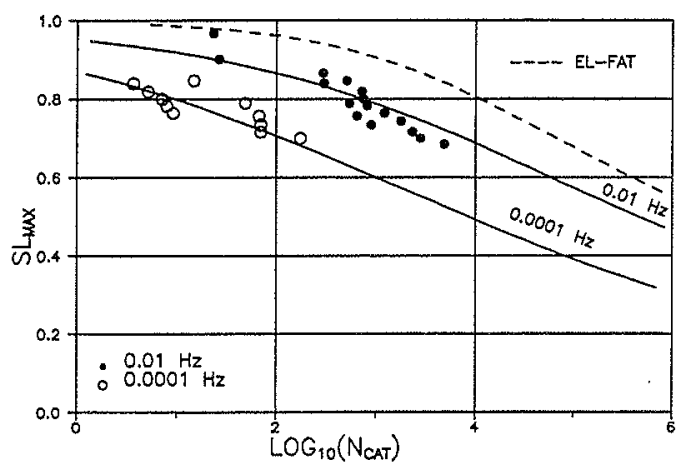

Figure 23. Lifetime of artificially damaged Douglas-Fir tensile loaded perp to grain with $p=0$. "El-fat" is lifetime predicted at very high frequency.

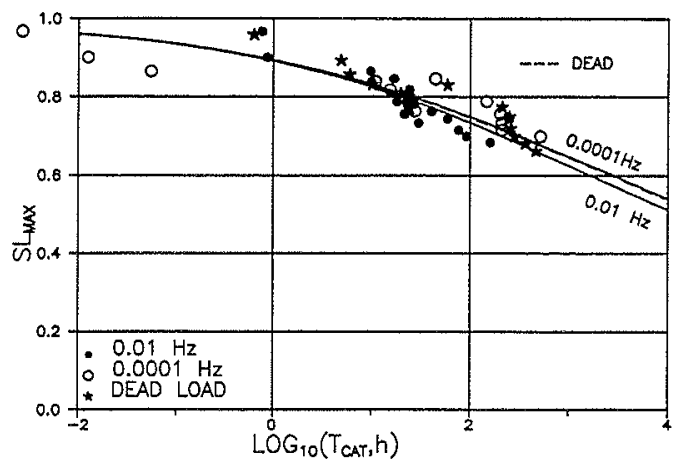

Figure 24. Lifetime of artificially damaged Douglas-Fir tensile loaded perp to grain with $p=0$. Predicted "dead" coincides practically with $f=1 . e-4 \mathrm{~Hz}$.

Figures 25 and 26: The experiments on Spruce glu-lam were made at a moisture content of $u=20 \%$. Thus, a low relaxation time is expected for plain spruce. However, a glue delaying effect on creep is thought to increase the relaxation time to $\tau=1$ day being used in the analysis.

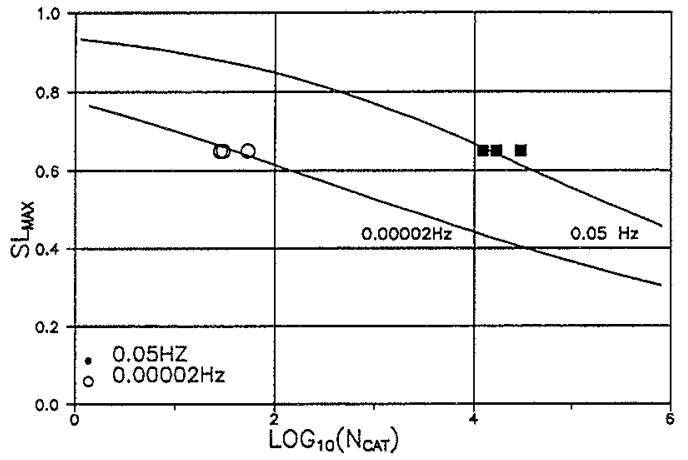

Figure 25. Lifetime of laminated spruce, bending with load ratio $p=0$.

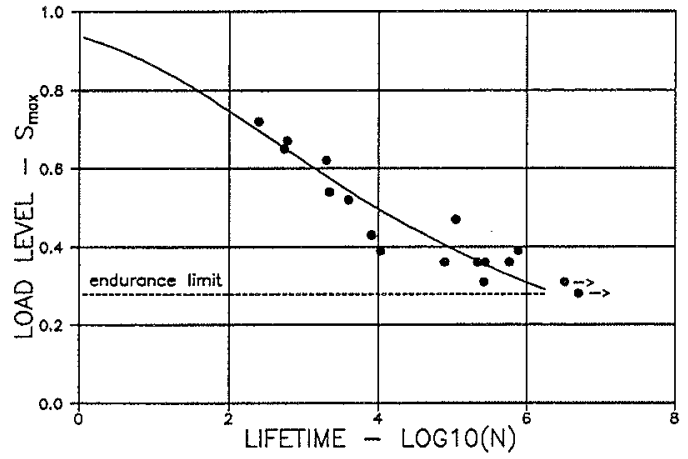

Figure 27. Lifetime of Pine-heartwood loaded in bending with $(p, f)=(-1,50 \mathrm{~Hz})$.

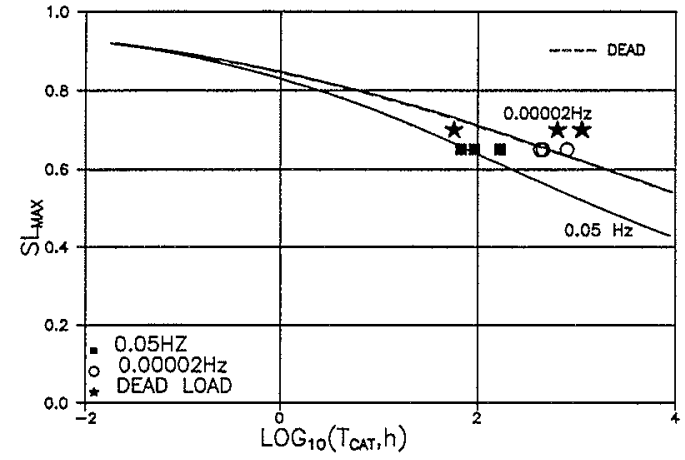

Figure 26. Lifetime of laminated spruce, bending with load ratio $p=0$.

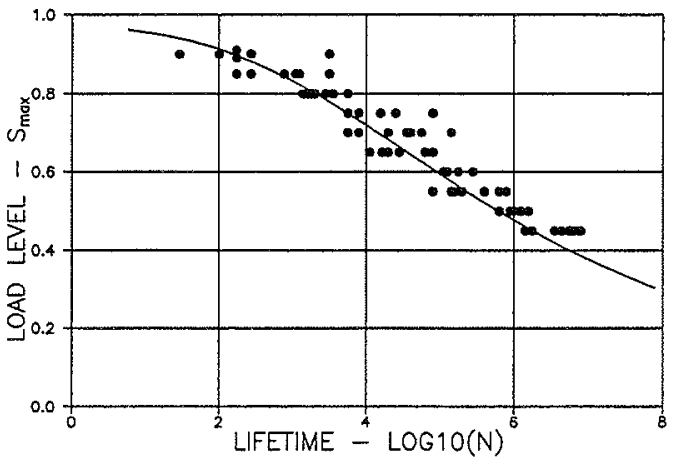

Figure 28. Lifetime of particle boards and hardboards loaded in tension and interlaminar shear with $(p, f)=(0.1,15 \mathrm{~Hz})$. 


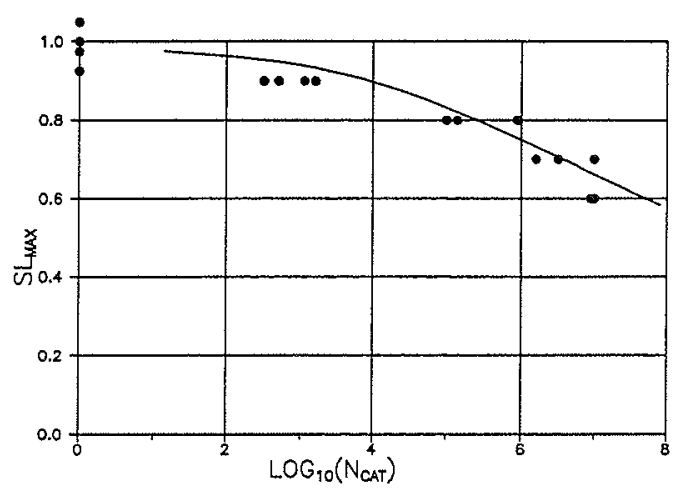

Figure 29. Lifetime of Khaya 4-ply loaded in bending with $(p, f)=(0.1,15 \mathrm{~Hz})$.

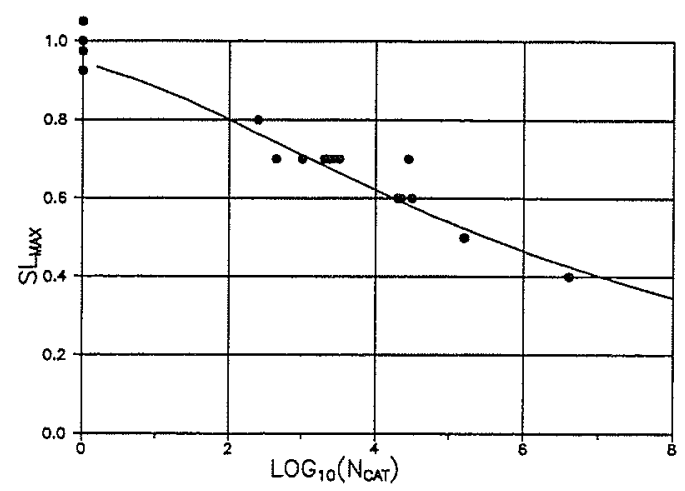

Figure 30. Lifetime of Khaya 4-ply loaded in reversed bending with $(p, f)=(-1$, $10 \mathrm{~Hz}$ ).

Figures 29 and 30: Apparently Khaya ply-wood does not creep and fail like other woods such as spruce and fir. A relaxation time of $\tau=10$ days might be explained by a creep delaying effect of the glue (epoxy) used. A fatigue parameter of $M=15$ (determined from the experimental results by Equation 47), however, cannot be explained immediately. Does Khaya wood have a more rough fatigue failure surface than other wood products? No information is given in (50) to evaluate the hypothesis made in Section 3.1 that increasing roughness increases $M$.

Figure 32: This experiment (53) on lifetime of spruce subjected to compressive repeated loads $\|$ to grain reveals a fatigue parameter of $M=12$. The question can be asked if the failure texture in this experiment is more rough than in the very similar experiment (46) illustrated in Figures 19 and 20 where $M=9$ was deduced. There is not enough information on failure texture in $(46,53)$ to decide on this question.

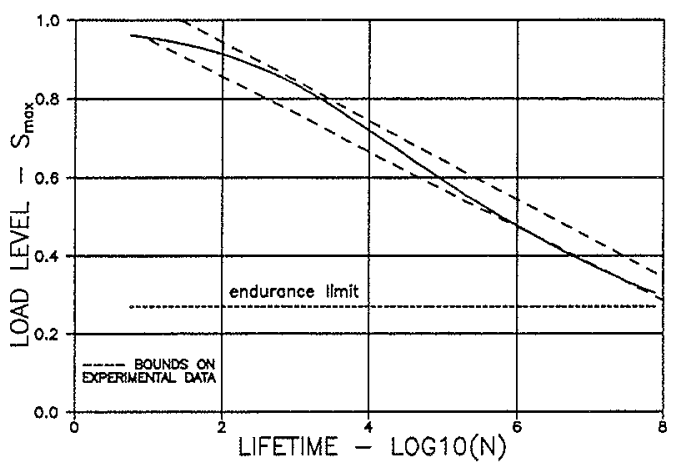

Figure 31. Lifetime of Doug-Fir fingerjoints loaded in tension /| grain with ( $p$, $f)=(0.1,15 \mathrm{~Hz})$.

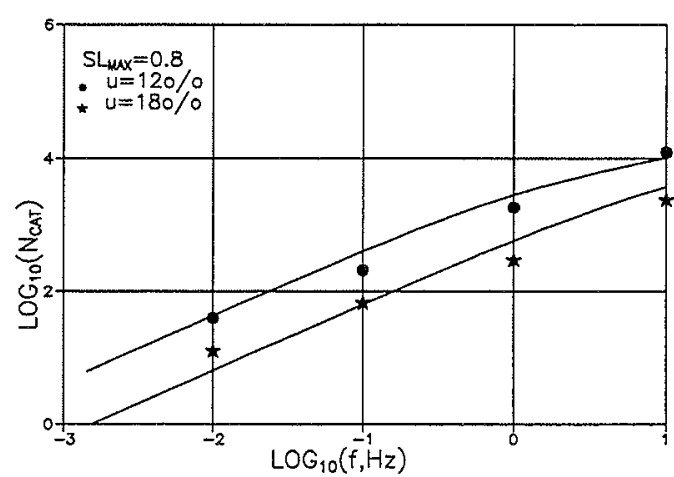

Figure 32. Fatigue of spruce considered in (53) compressed with $S L_{M A X}=0.8$ parallel to grain with $p=0$. 


\section{Special observations}

\section{Load ratio and moisture}

Figure 33 demonstrates how the theory predicts lifetime to change with load ratio. The material and fatigue load assumed are the same as referred to in Figure 30: Khaya Ply subjected to $10 \mathrm{~Hz}$ fatigue (50).

The predicted results agree in orders of magnitudes with test results reported in (54) for this test setup. A detailed discussion between the two set results in (50) and (54) cannot be made, however, as the tests in the latter reference were made with load dependent frequencies. A special "saw-tooth" load procedure was applied with constant rate of loading (up and down) which implicates a test frequency as predicted in Figure 35, reproduced from (5), which clearly disregards any influence of creep on fatigue.

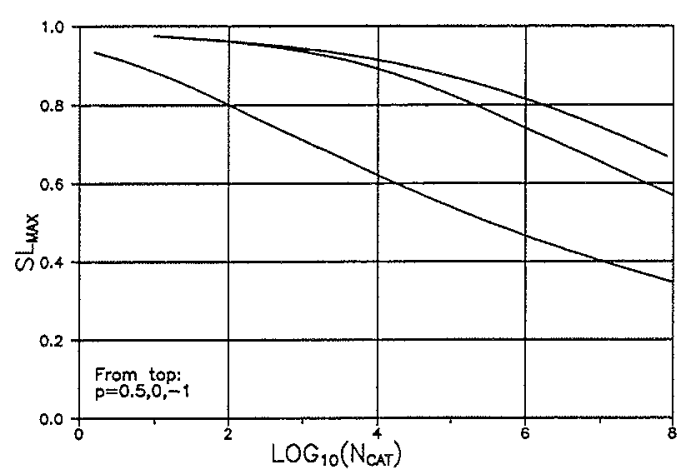

Figure 33. Predicted influence of load ratio on Khaya lifetime at $f=10 \mathrm{~Hz}$.

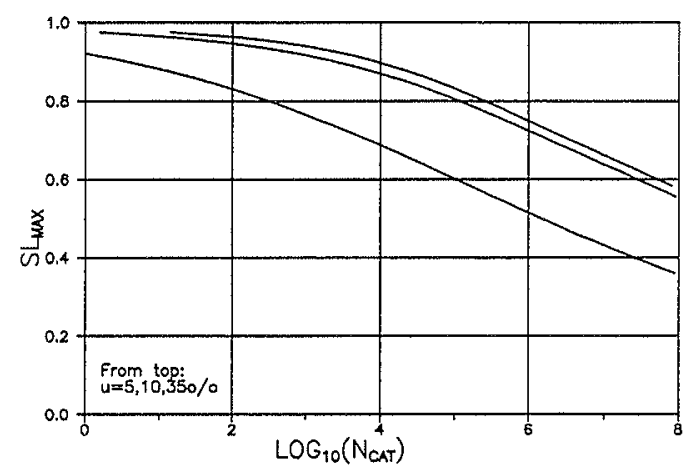

Figure 34. Predicted influence of moisture content on Khaya lifetime at $f=15 \mathrm{~Hz}$. $d_{U}=\left(u_{R E F}-u \%\right) / 5$ is used.

Figure 34 demonstrates how the theory predicts lifetime to change with moisture

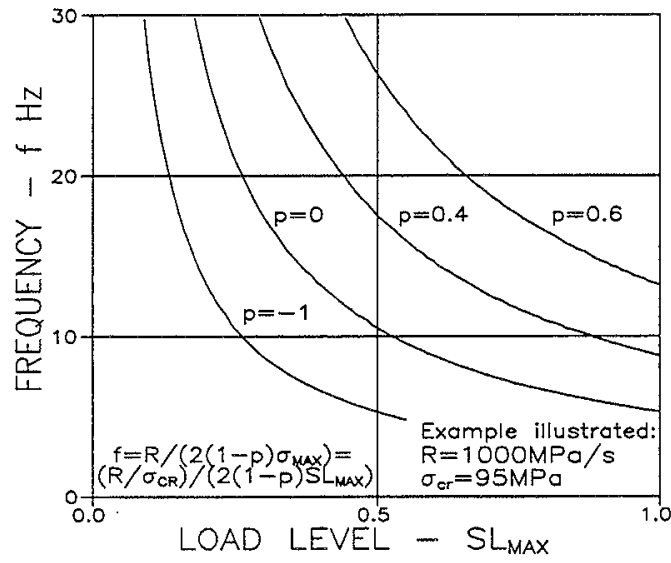

Figure 35. Load dependent frequency used by Ansell. contents. The material and fatigue load assumed are the same as referred to in Figure 29: Khaya Ply subjected to $15 \mathrm{~Hz}$ fatigue (50). The predicted results agree in order of magnitudes with test results reported in (54) for this test setup. A detailed discussion between the two set results cannot, however, be made as the tests in (5.4) were made with load dependent frequencies caused by the 
special "saw-tooth" load procedure previously discussed disregarding any influence of creep on fatigue.

\section{Peak loading}

Peak loading is block loading according to Figure 1 with fraction of time $\beta$ under max load being considerably different from the $B=0.5$ hitherto considered. The theory presented in this paper predicts relatively little difference between $\beta=0.5$ lifetime and peak load lifetime with $B=1$ (constant load with instant off/on loadings). This is illustrated in Figure 36 with $(\mathrm{p}, \mathrm{f})=\left(0,10^{-4} \mathrm{~Hz}\right)$. Peak load lifetime with $B=0$ (constant load with instant on/off loadings) is shifted to longer lifetimes with less than $1 / 4$ decade relative to lifetime with $B=0.5$. This shift is reduced to almost nothing at increasing load frequency. We may summarize these observations as follows: Lifetime is practically independent of $B$ at load frequencies higher than $\mathrm{f}=10^{-5}-10^{-4} \mathrm{~Hz}$.

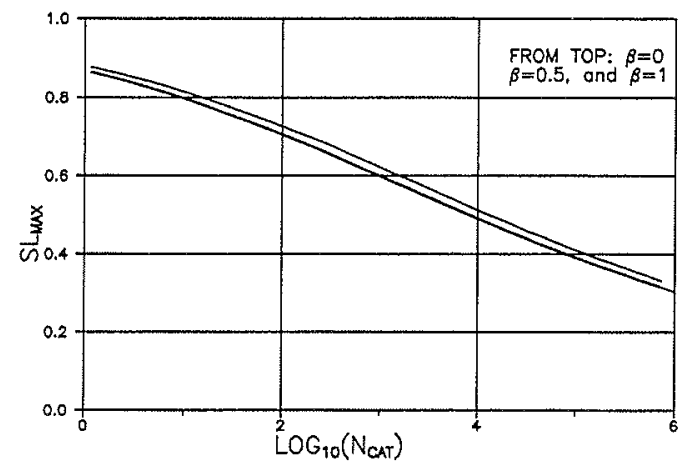

Figure 36. $(F L, b, \tau)=(0.2,1 / 3,0.5$ day $)$, $\left(C, M, p_{C R}, D_{T H}\right)=(3,9$, neg, 0$),(p, f)=(0$, $\left.10^{-4} \mathrm{~Hz}\right)$

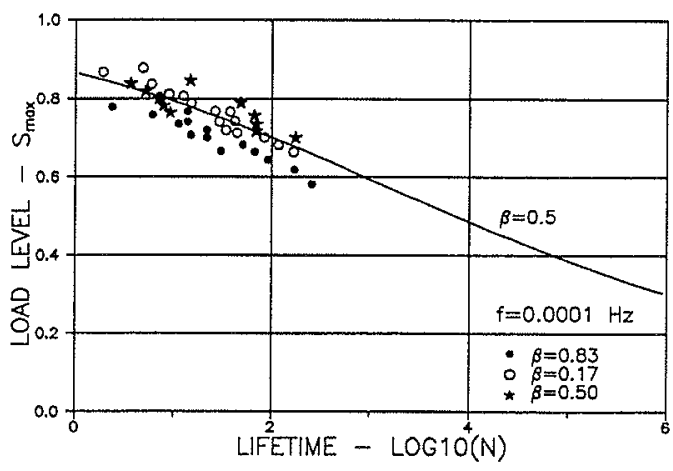

Figure 37. Lifetime of artificially defected Douglas-Fir tensile loaded perp to grain, load ratio $p=0$. (PILOT TESTS).

The experiments (38) previously referred to in Figures 23 and 24 on artificially defected Doug-Fir specimens were designed for $\beta=0.5$ load histories. Some pilot experiments, however, were made to look at the influence of $B \neq 0.5$. The results are presented in Figures 37 and 38 together with the $\beta=0.5$ results from Figure 23 , including the theoretical lifetime prediction (solid line).

Considering the large data scatter which is usually associated with lifetime experiments Figure 37 seems to confirm the statement that lifetime is not very much influenced by fractional time $B$ under maximum load.

A somewhat peculiar behavior of lifetime data is noticed in Figure 38. Almost the same lifetime is observed for $B=0.17$ and $B=0.83$ at a frequency of $f=0.01$ Hz. This "common" lifetime is shorter than lifetime at $B=0.5$. These observations 


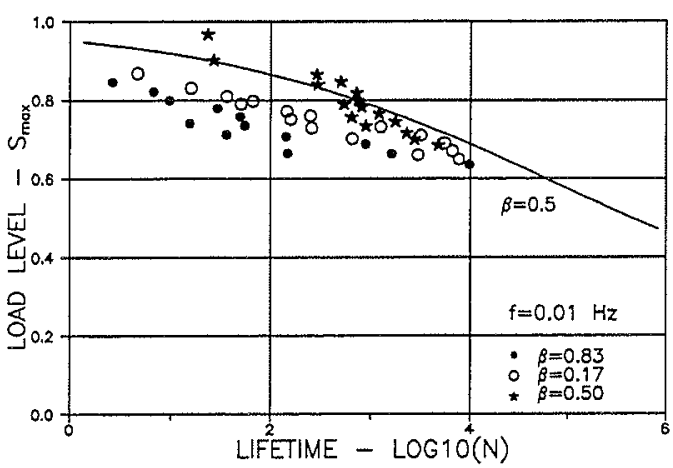

Figure 38. Lifetime of artificially defected Douglas-Fir tensile loaded perp to grain, load ratio $p=0$. (PILOT TESTS $)$. can, in the autho opinion, only be explained as a result of a missing ability of the very simple test set-up to handle fast block load variations: At $\mathrm{f}=0.01 \mathrm{~Hz}$ with $B=0.17$ and $B$ $=0.83$ the scissor table, see Figure 22 , moves up and down within an average of 17 seconds with the result that the test specimen is "overloaded" due to forces of inertia and other disturbances in the test system. This feature will magnify the energy dissipation due to crack opening alternation ( $\mathrm{Z}$ in Equation $35 \mathrm{fx}$ ) with the result that shorter lifetimes are experienced.

\subsection{Residual strength}

The DVM-theory has been shown in (7) to predict residual strength very well for wood subjected to static load. In fact, this feature was used qualitatively by Borg Madsen and co-workers $(55,56)$ to verify the theory and its underlying materials concept by identifying different stages of crack propagation in wood. As previously stated, residual strength of wood subjected to repeated load can be predicted very easily at the same time as lifetime is predicted by the algorithm in Chapter 4. Two examples are presented in Figures 39 and 40. Unfortunately no experimental data have been found by the author to verify these predictions.

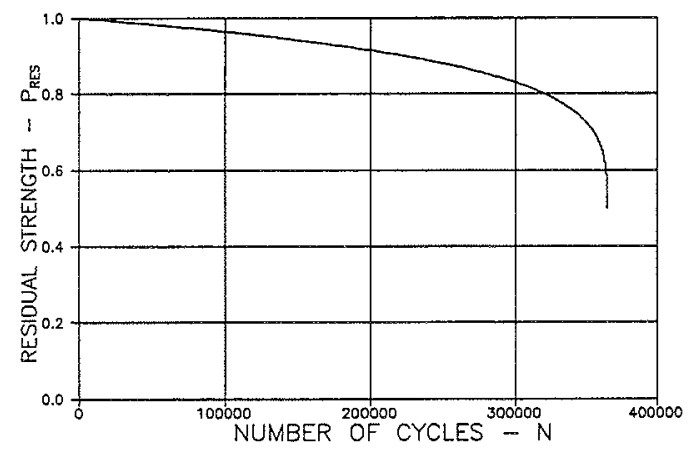

Figure 39. Residual strength at $\left(S_{M A X}, p, \beta\right.$, $f)=(0.5,0,0.5,0.1 \mathrm{~Hz})$.

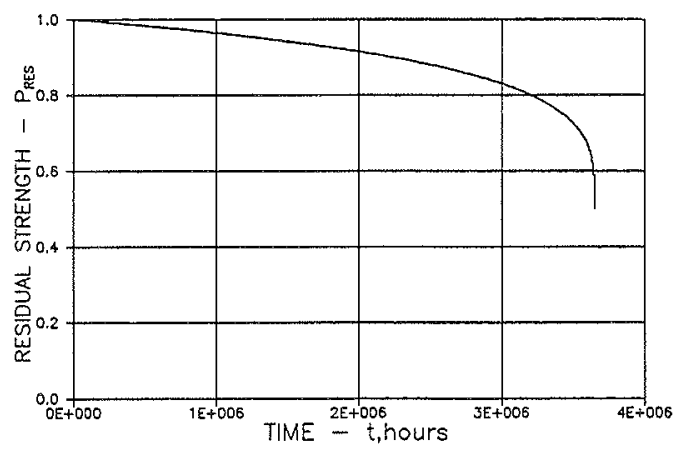

Figure 40. Residual strength at $\left(S_{M A X}, p, \beta\right.$, $f)=(0.5,0,0.5,0.1 \mathrm{~Hz})$.

Material data for Figures 39 and 40 are: $(\mathrm{FL}, \mathrm{b}, \tau)=(0.4,0.25,1$ day $),\left(\mathrm{C}, \mathrm{M}, \mathrm{p}_{\mathrm{CR}}\right.$, $\left.\mathrm{D}_{\mathrm{TH}}\right)=(3,9$, neg, 0$)$. 


\subsection{Discussion}

Material properties and fatigue parameters have been deduced in Section 5.2 from comparing experimental lifetime data with theoretically predicted lifetime data. A satisfactory agreement has been found between these deduced quantities and the OM-estimates (order of magnitude) set up in Section 5.1.

Relaxation times $\tau$ and fatigue rate powers $\mathrm{M}$, however, do not fully agree with the OM-estimates. The former observation is expected as there are not sufficient creep measurements presented in the literature which can support better estimates. The latter observation cannot be immediately explained. Rate powers of $M \geq 9$ apply. The most common value, however, is $M=9$ by which the shorter lifetimes are predicted. A damage rate constant of $\mathrm{C}=3$ seems to valid in general.

Critical load ratios of $\mathrm{p}_{\mathrm{CR}} \approx-0.6$ to -0.75 have been deduced which are somewhat lower than the OM-estimate of $\mathrm{p}_{\mathrm{CR}}=-0.5$ in Section 5.1. For load ratios $\mathrm{p}<0$ shorter lifetimes are predicted with $\mathrm{p}_{\mathrm{CR}} \rightarrow-1$. In the present context $\mathrm{p}_{\mathrm{CR}}=-0.75$ is the safer value (with respect to lifetime prediction).

Arguments are presented indicating that lifetime is not very much influenced by fractional time of maximum loading $B$ when frequencies are $f>10^{-5}-10^{-4} \mathrm{~Hz}$. The shorter lifetimes are predicted with $\beta=1$ corresponding to a time shift factor of $\mathrm{h} \equiv 1$, see Equation 32 . 


\section{Conclusions and final remarks}

A satisfactory agreement has been demonstrated in Chapter 5 between theory and experiments made at ambient temperatures of $\mathrm{T} \approx 20^{\circ} \mathrm{C}$ and moisture contents of $\mathrm{u} \approx 10-18 \%$. Frequencies and load ratios considered are $\mathrm{f}=0$ (dead) to $50 \mathrm{~Hz}$ and $\mathrm{p}=-1$ to 1 .

It can be concluded that the theory is basically sound and that safe estimates of lifetime and residual strength, within ranges of load and climatic conditions considered in Chapter 5, can be made by the theory when relaxation time $\tau$ is known and fatigue parameters are introduced with $\left(C, M, p_{C R}, D_{T H}\right)=(3,9,-0.75,0)$ together with a time shift factor of $h \equiv 1$. The estimates such calculated consider any fractional time under maximum load.

The quality of lifetime estimates in practice depends very much on the quality of relaxation time estimates used as theoretical in-put. The ideal relaxation time to use is the one which defines creep in front of damage areas. In practice this ideal value is very hard, or impossible, to get. In most cases we have to estimate the relaxation time as indicated in Section 5.1 from creep experiments on bulk wood.

Shorter lifetimes are predicted by the theory at increasing moisture content. Lifetime in general is inversely proportional with quality of wood (FL), meaning, for example, that structural wood has a longer lifetime than clear wood subjected to similar load levels ( $\left.\mathrm{SL}_{\mathrm{MAX}}, \mathrm{p}\right)$.

The following statements made in Chapter 1 are strongly emphasized by the theory: Fatigue design of wood members cannot be based on the concept of a critical number of load cycles. Severe mistakes can be made by doing so. The number of load cycles to failure of wood, for example, may decrease more than 100 times lowering the frequency from 1 cycle per 10 seconds to 1 cycle per 2 hours. Thus, parameters needed in fatigue design of wood cannot be determined from accelerated tests.

Examples are demonstrated in the following sections on how the theory can be utilized in practice: Design graphs are presented in Section 6.1. A generalization of the theory is presented in Section 6.2 which considers lifetime and residual strength of wood subjected to some non-harmonic load variations. Potentials of the theory to be used on other materials are discussed in Section 6.3. Finally, some future projects are outlined in Section 6.4. 


\subsection{Design - master graphs}

Any result obtained in this paper can be presented in so-called master-graphs where lifetime and residual strength can be related to frequency and time under load as shown in Figures 41 - 44. This feature is a result of the extensive use which has made in the analysis of non-dimensional (or normalized) strength, load, time, and frequency. It seems justified to suggest the hypothesis for practice that the fatigue behavior of wood and wood related materials in general (including material with fingerjoints) can be described/predicted by common master-graphs irrespective of loading mode. The hypothesis has recently been successfully tested in (4) on glu-lam beams with various slopes of lamella.

Figures 41-44 apply for safe predictions, meaning that any fractional time under maximum load is considered, and that the underlying fatigue parameters are those presented in the introductory paragraph of this chapter.

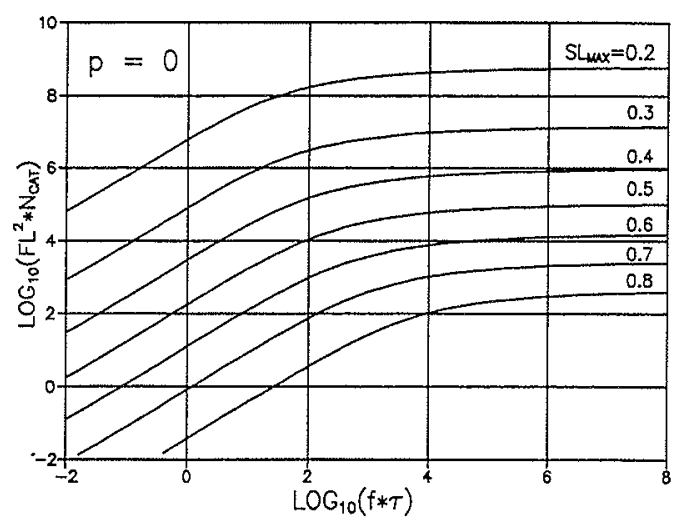

Figure 41. Master graph for number of cycles to failure in wood with creep power $b=0.25$.

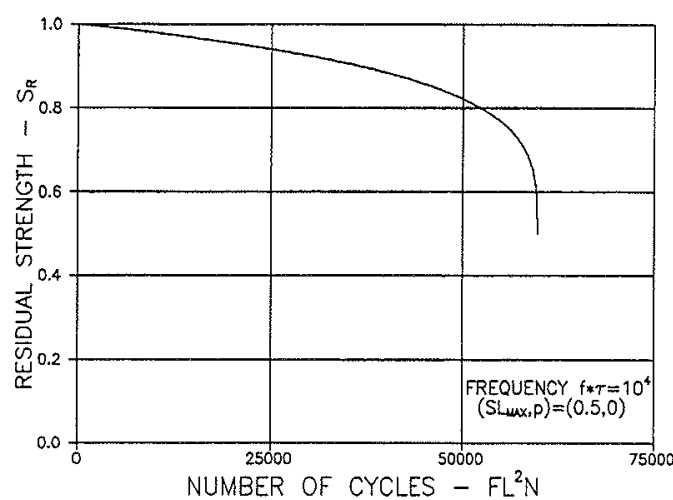

Figure 43. Master graph for residual strength of wood with creep power $b=$ 0.25 as related to number of cycles.

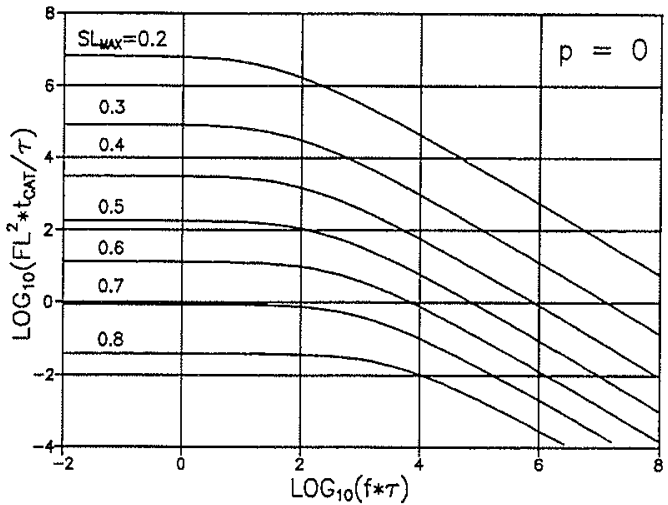

Figure 42. Master graph for time to failure in wood with creep power $b=0.25$.

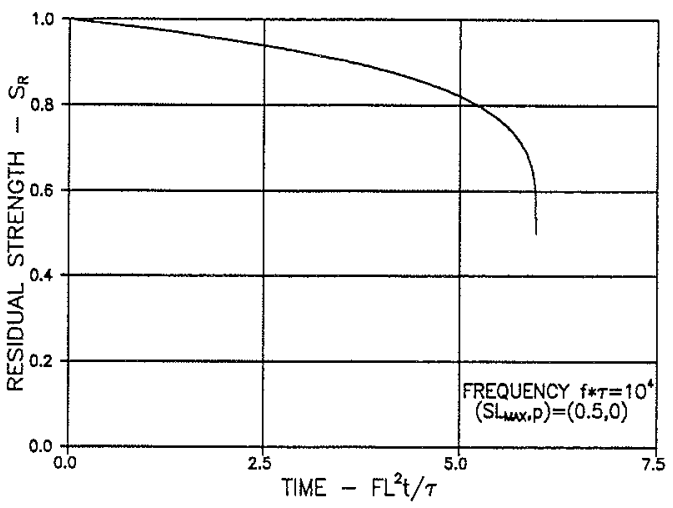

Figure 44. Master graph for residual strength of wood with creep power $b=$ 0.25 as related to time. 
It is noticed from the master graphs shown in Figures 41 and 42 that lifetime is practically not influenced by creep at non-dimensional load frequencies $f * \tau>10^{6}$. At the other hand lifetime is practically not influenced by load frequencies at $f^{*} \tau$ $<1$. In a transition area $1<\mathrm{f}^{*} \tau<10^{6}$ (5 decades) both creep and elastic fatigue mechanisms are active. Easy safe estimates for $\mathrm{p}=0$ can be made as shown in Equation 49.

Lifetime $=\left(\begin{array}{ll|}\text { dead load lifetime }(\text { Eqs 43,44) } & \text { when } f \tau<1 \\ \text { elastic fatigue lifetime }(\text { Eqs 27,28) } & \text { when } f \tau>10^{5} \\ \text { straigth line log-log interpol } & \text { when } 1<f \tau<10^{5}\end{array}\right.$

From Figures 43 and 44 is observed that strength reduction starts becoming serious when the material considered has experienced $1 / 3$ of its lifetime. The transition area of 5 decades between plain elastic lifetime and plain deadload lifetime shifts to higher frequencies at increasing load ratio p. It drops to lower frequencies at decreasing load ratios. The statement on strength reduction keeps valid.

\subsection{Non-harmonic load variation}

Non-harmonic load variations such as illustrated by examples in Figures 45 and 46 can also be considered by the prediction method presented in this paper: Local load frequencies must be essentially higher than frequency of the local enveloping $\mathrm{SL}_{\mathrm{MAX}}$-line. Sections of load history with load fractions $\mathrm{p}=1\left(\mathrm{SL}_{\mathrm{MAX}}=\mathrm{SL}_{\mathrm{MIN}}=\right.$ SL) must have non-negative slopes (or some negative slopes restricted by Eq. 42).

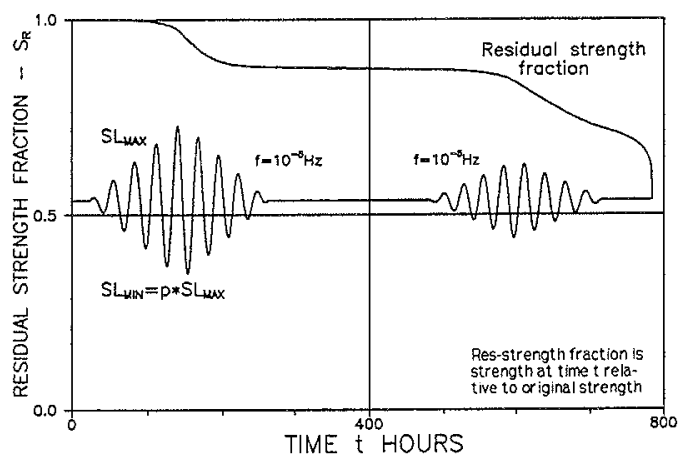

Figure 45. Residual strength and lifetime of wood subjected to load as indicated with $(F L, b, \tau)=(0.4,0.25,1$ day).

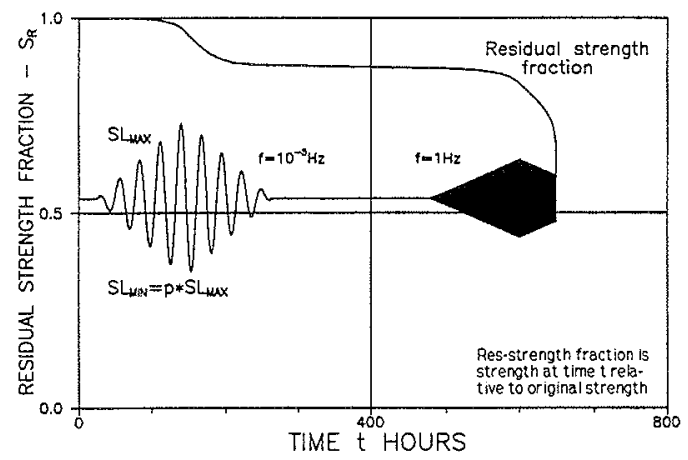

Figure 46. Residual strength and lifetime of wood subjected to load as indicated with $(F L, b, \tau)=(0.4,0.25,1$ day $)$.

With these conditons held we may easily modify the algorithm previously presented to consider other load variations (than harmonic variations). We proceed 
stating that rate of damage $\mathrm{d} / \mathrm{dt}=\mathrm{f}^{*} \mathrm{FL}^{2} / \mathrm{X}$ (see Equation 37) at time $\mathrm{t}$ is defined by state of damage and load specifications at that time only. Then we just have to introduce a subroutine into the algorithm presented in Table 1 which updates $\left(S L_{\text {MAX }}, p, f, B\right)$ as functions of time $t$, immediately followed by updated $\kappa$-steps. A generalized algorithm is presented in Appendix $A$ at the end of the paper.

Simple examples of residual strength and lifetime predictions by this algorithm are shown in Figures 45 and 46 . The same basic assumptions of $\mathrm{h} \equiv 1$ and $\mathrm{p}_{\mathrm{CR}}=$ -0.75 are assumed as justified in the introductory paragraph of this chapter.

For load variations considered in this section the generalized algorithm presented in Appendix $\mathrm{A}$ is suggested as a qualified alternative to the well-known Palmgren-Miner's method $(57,58)$ normally used in the field of lifetime prediction of materials subjected to arbitrary load variations. The Palmgren-Miner's method, however, does not consider the influence of creep on fatigue and is therefor not reliable in fatigue analysis of wood, especially at low load frequencies.

\subsection{Other viscoelastic materials}

\section{Glass fiber reinforced epoxy}

Wood has been the prime material considered in this paper. Other materials with Power-law creep, however, can also be considered by the lifetime theory develo-

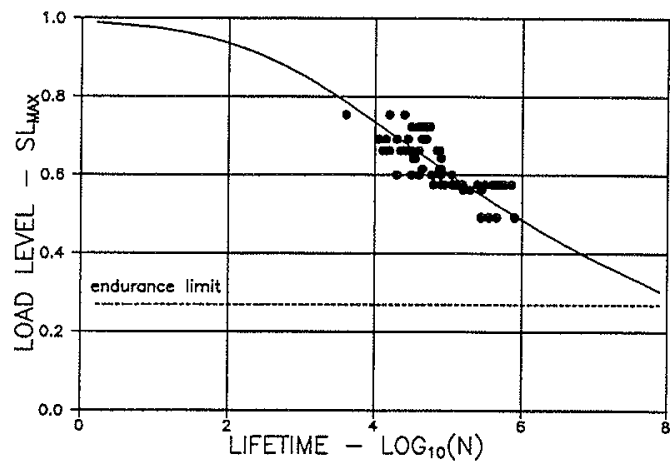

Figure 47. Fatigue lifetime of glass fiber reinforced epoxy. Tension in fiber direction. Predictions for $f=19-34 \mathrm{~Hz}$ coincide. ped. An example is shown in Figure 47 where life time data are presented from fatigue tests with $(\mathrm{p}, \mathrm{f})=(0.1$, 19-34 $\mathrm{Hz}$ sinus) on uni-directionally glass fiber reinforced epoxy (59) loaded in tension $\|$ to fibres. Lifetime prediction is made with (FL,b, $\tau)=(0.4,0.25,1$ day $)$ and $\left(\mathrm{C}, \mathrm{M}, \mathrm{p}_{\mathrm{CR}}\right.$, $\left.\mathrm{D}_{\mathrm{TH}}\right)=(3,9$, neg, 0.0001). A reference strength of $\sigma_{\mathrm{CR}}=1320 \mathrm{MPa}$ is estimated by "backwards" extrapolation to a few number of cycles on the experimental real stress- $\mathrm{N}_{\mathrm{CAT}}$ graph. It is noticed from the figure that there is practically no influence of frequency on lifetime. This means that lifetime is not influenced by creep at frequencies used in the experiments. 


\section{Aging viscoelastic materials - concrete}

The lifetime theory developed in this paper can easily be generalized to apply for viscoelastic materials others than such defined by Power-law creep. The principles in this paper just have to be combined with a more general handling of creep functions as described in (e.g. 13,60). A more easy way, however, to analyze numerically the fatigue behavior of materials not exhibiting Power-Law creep is to subdivide time into intervals where creep is approximated to follow a Power Law description. The algorithms presented in this paper can easily be adapted for this purpose by introducing a "creep conversion" subroutine at the top of the programs. This subroutine may also consider viscoelastic materials with time dependent strength and creep. Applications of the algorithms such extended have been demonstrated in $(61,62,63)$ to predict the fatigue behavior of concrete and other aging viscoelastic materials.

\subsection{Some future research}

Relaxation time at crack fronts has been identified in this paper as the prime material parameter responsible for the viscoelastic part of fatigue. At low load frequencies it is justified to estimate this parameter from moisture content and temperature in resting (not loaded) wood. At high frequencies it might not be justifiable. In crack front areas large amounts of heat may develop from crack closure mechanisms which will increase local temperature dramatically. This may change relaxation time and fatigue parameters $\left(\mathrm{C}, \mathrm{M}, \mathrm{p}_{\mathrm{CR}}, \mathrm{D}_{\mathrm{TH}}\right)$ significantly - and consequently also lifetime of the material considered.

With respect to the viscoelastic part of fatigue: Higher load frequencies provoke local temperatures to increase which lower the local moisture content. From a fatigue point of view two counter-acting mechanisms are then activated. Damage rate increases with increasing temperature (reducing $\tau$ ), while damage rate decreases with decreasing moisture content (increasing $\tau$ ). In the authors opinion (obtained by inspection of various fatigue experiments) the two effects neutralize each other at frequencies $\mathrm{f}<$ approximately $15 \mathrm{~Hz}$, meaning that fatigue analysis at lower frequencies can be based on climatic conditions applying for resting wood.

It is emphasized, however, that this simple approach is purely empirical. Better estimates can only be achieved through more basic research on load induced local climates, on viscoelasticity in crack front areas, and on the general influence of moisture and temperature on material properties and fatigue parameters. The crack closure model presented in this paper may be useful in this context. Local tempe- 
ratures can be calculated from energy dissipation in crack front areas as represented by Equation 33 for example.

Finally, a method is needed very much in practice by which lifetime and residual strength can be estimated for wood subjected to real arbitrary load variations. More efforts should be made, theoretically and experimentally, to develop such a method. In this context it might be worthwhile to test the possibilities of using the algorithm presented in Appendix A (regardless of theoretical conditions) as a point of departure in developing an approximate method by which experimental data can be described sufficiently well. Alternatively, a semi-theoretical approach for lifetime estimation might be established modifying the Palmgren-Miner's method to consider creep implementing lifetime solutions for harmonic load variations as predicted by the algorithm presented in Table 1. 



\section{Appendix A - Non-harmonic load variation}

TABLE A. Lifetime and res-strength of wood: Non-harmonic load variation.

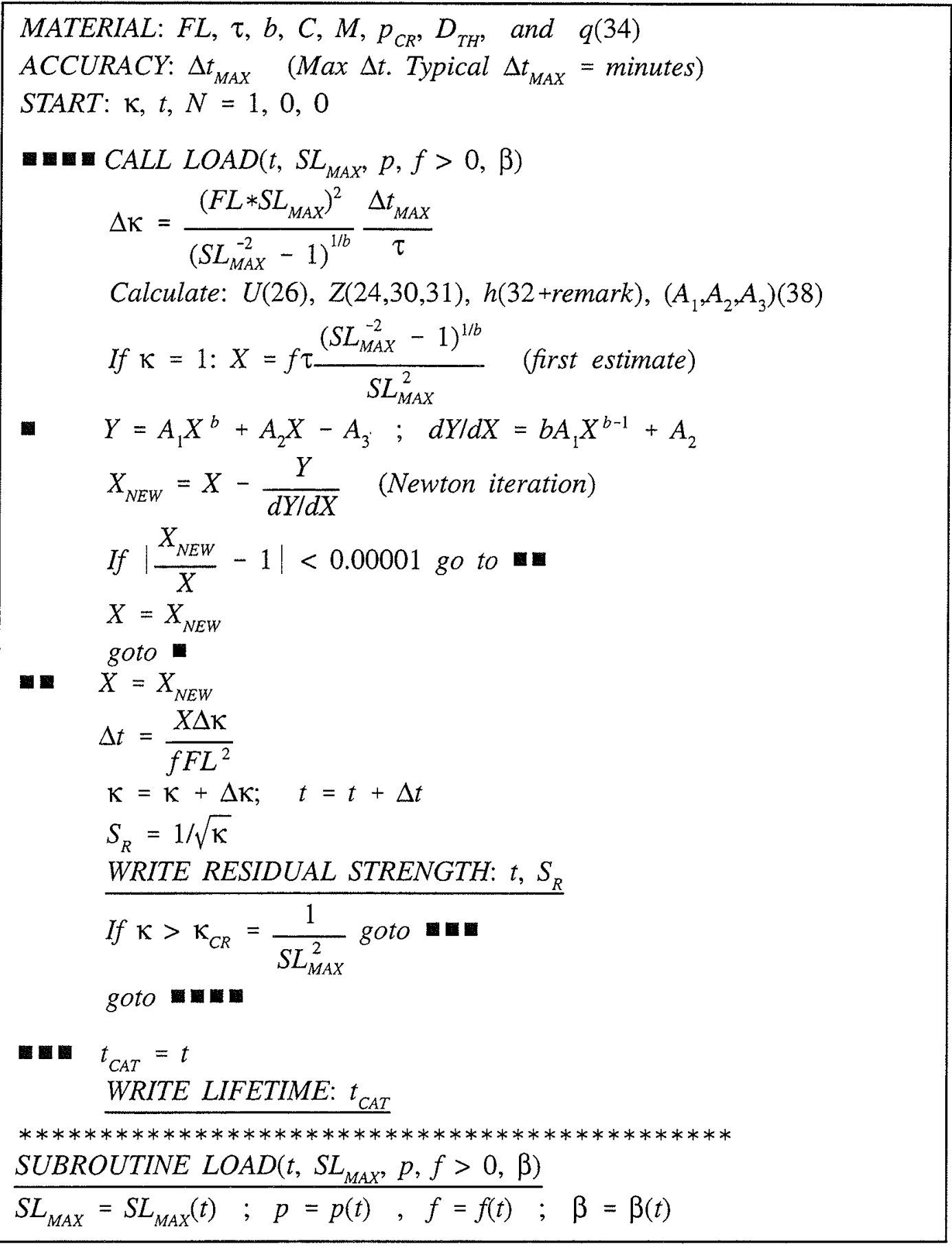

The algorithm in Table 1 used to predict lifetime and residual strength of wood subjected to harmonic load variations is generalized in Table A such that also some non-harmonic load variations can be considered. Classes of variations and 
the principles of generalization are outlined in Section 6.2 in the main text. Notice that a more refined $\Delta \kappa$-expression is used which is activated at every cycle of calculation. The accuracy of analysis migth be increased with smaller $\Delta t_{\text {MAX }}$ introduced. Depending on the problem studied it might be necessary to vary $\Delta t_{\operatorname{MAX}}$ in analysis until no further improvement of results are obtained. 


\section{Literature}

1. Nielsen, L. Fuglsang: "Lifetime and Fatigue of Wood and other Building Materials", Conference of Int. Union of Forestry Research Organizations (IUFRO), Saint John, New Brunswick, Fredericton, N.B., Canada, July 30 to August 3, 1990. Proc., Build. Mat. Lab., Techn. Univ. Denmark 1991, 448-482.

2. Idem: "Elastic Fatigue of Wood and other Building Materials". Building Mat. Lab., Techn. Univ. Denmark, Technical Report 170A(1986).

3. Idem: "Fatigue of Wood as related to Defects and Creep". Building Mat. Lab., Techn. Univ. Denmark, Technical Report 170B(1987).

4. Idem: "Træs udmattelse - prediktion af træbjælkers levetid og reststyrke" (in danish, "Fatigue of wood - prediction of lifetime and residual strength of wooden beams"), Final report on government supported project on "Fatigue of glu-lam beams", Tech. rep. 294(1993), Build. Mat. Lab., Tech. Univ. Denmark.

5. Idem: "Beskrivelse af engelske fatigue-resultater fra forsøg med Khaya 4-lags laminat", (in danish, A critical review on english fatigue results on Khaya 4-ply laminate). Report 2(1991) in a government supported project on Advanced Materials based on Straw and Wood. Also available as Tech. Rep. 345(1995), Build. Mat. Lab., Tech. Univ. Danmark.

6. Nielsen, A.: "Rheology of Building Materials". Thesis, Statens Institut för Byggnadsforskning, Stockholm, Document D6(1972).

7. Borg Madsen: "Structural Behavior of Timber", Timber Engineering Ltd., North Vancouver, B.C., Canada 1992. Appendix A by L. Fuglsang Nielsen: "The theory of Wood as a Cracked Viscolastic Material".

8. Nielsen, L. Fuglsang: "Crack Failure of Dead-, Ramp-, and Combined Loaded Viscoelastic Materials", First Int. Conf. on Wood Fracture, Banff, Alberta, Canada, august 1978. Proc. Western Forest Products Lab., Univ. Brit. Columbia, Vancouver, Canada, $1979,187-200$.

9. Nielsen, L. Fuglsang and Kousholt, K.: "Stress-Strength-Lifetime Relationship for Wood", Wood Science, 12(1980), 162.

10. Nielsen, L. Fuglsang: "Lifetime, Residual Strength, and Quality of Wood - and other viscoelastic materials". Holz als Roh- u. Werkstoff, 49(1991), 451-455.

11. Idem: "Lifetime of wood as related to strength distribution", in "Reliability-Based Design on Engineered Wood Structures", (ed. J. Bodig), Kluwer Academic Publishers, Dordrecht, The Netherlands, 1992.

12. Idem: "Drying of Wood - Stresses Caused by Drying", Bygningsstatiske Meddelelser, 57(1986), 73 - 100.

13. Idem: "A Lifetime Analysis of Cracked Linear Viscoelastic Materials - with Special Reference to Wood". IUFRO-Engineering Group Conference 1982, Borås, Sweden. Proc. Chalmers Univ. of Technology, Dept. Civil Eng., Gothenburg 1982, pp. 151 - 178.

14. Idem: "Wood as a Cracked Viscoelastic Material, Part I and II" International Workshop on Duration Of Load in Lumber and Wood Products, sept. 1985, Vancouver, 
B. C., Canada. Proc. FORINTEK, Western 1 rest Products Lab., Vancouver, B. C., Canada, Spec. Publ. No. SP-27(1986): 67 - 89.

15. Alfrey, T.: "Non-Homogeneous Stresses in Viscoelastic Media". Qu. Appl. Math. 2(1944), 113.

16. Flügge, W.: "Viscoelasticity". Blaisdell Publishing, London 1967.

17. Clouser, W. S.: "Creep of small Wood Beams under constant Bending Load". U.S. Forest Products Lab., Report 2150(1959).

18. Nielsen, L. Fuglsang: "Power Law Creep as related to Relaxation, Elasticity, Damping, Rheological Spectra and Creep Recovery - With Special Reference to Wood". IUFRO-Engineering Group Conference 1984. Xalapa, Mexico. Proc. Techn. Univ. Denmark, Build. Mat. Lab., Copenhagen 1984, 181-204.

19. Dugdale, D. S.: "Yielding of Steel Sheets containing Slits". J. Mech. and Phys. of Solids, 8(1960), 100-104.

20. Tada, H., Paris, P. C. and Irwin, G. R.: "The Stress Analysis of Cracks Handbook". Del Res. Corp., Hellertown, Pa. 1973.

21. Nielsen, L. Fuglsang: "Materials Mechanics" (in danish). Textbook, Build. Mat. Lab., Tech. University of Denmark. Tech. Report 189(1988).

22. Griffith, A. A.: "The Phenomenons of Rupture and Flow in Solids". Trans. of the Royal Soc. of London, Series A, 221(1920) 163-198.

23. Rice, J. R.: "Mechanics of Crack-Tip Deformation and Extension by Fatigue". Fatigue Crack Propagation, ASTM STP 415(1967), 247-311.

24. Elber, W:: "Fatigue crack closure under cyclic tension", Engineering Fracture Mechanics, 2(1970), 37-45.

25. Weertman, J.: "Rate of Growth of Fatigue Cracks calculated from the Theory of infinitesimal Dislocations distributed on a Plane". Int. Journ. Fracture Mech., 2(1966), 460-467.

26. Paris, P. and F. Erdogan, F.: "A critical Analysis of Crack Propagation Laws". Journ. of Basic Engineering, Trans. ASME, 85(1963), 528-534.

27. Irving, P. E. and McCartney, L. N.: "Prediction of Fatigue Crack Growth Rates: Theory, Mechanisms and Experimental Results". Fatigue 77 Conference, Proc. Univ. of Cambridge, Metal Science, Aug/Sept, 1977, 351.

28. Madsen, H. O.: "Deterministic and Probabilistic Models for Damage Accumulation due to Time Varying Loading". DIALOG, 5(1982), Engineering Academy of Denmark, Dept. Struct. Eng., Copenhagen

29. Elber, W.: "The Significance of Fatigue Crack Closure". Damage Tolerance in Aircraft Structures, ASTM STP 486(1971), 230-242.

30. Imhof, E. J. and Barsom, J. M.: "Fatigue and Corrosion-Fatigue Crack Growth of 4340 Steel at Various Yield Strengths". Symp. on Progress in Flaw Growth and Fracture Toughness Testing, 28-30 August 1972, Philadelphia, Pa., ASTM SP. Techn. Publ. 536(1973), Baltimore, Md., 182-206. 
31. Illston, J. M., Dinwoodie, J. M. and Smith, A. A.: "Concrete, Timber and Metals". Van Nostrand Reinhold Comp., New York 1979.

32. Hettzberg, R. W., Manson, J. A. and Wu, W. C.: "Structure of Polymers and Fatigue Crack Propagation". Symp. on Progress in Flaw Growth and Fracture Toughness Testing, 28-30 August 1972, Philadelphia, Pa., ASTM SP. Techn. Publ. 536(1973), Baltimore, Md., 391-403.

33. Wendy, Lee: "Crack Growth Studies on Wood". Dept. Metallurgy, Univ. Brit. Columbia, Vancouver, B. C., Canada, Techn. report, spring 1983.

34. Kollmann, F. P. and Côté, W. A.: "Principles of Wood Science and Technology. I: Solid Wood". Springer Verlag, Berlin 1968.

35. McCarver, J. F. and Ritchi R.O.: "Fatigue Crack Propagation Thresholds for long and short Cracks in René 95 Nickel-base Superalloy". Materials Science and Engineering, 55(1982), 63-67.

36. Schniewind, A. P. and Lyon, D. E.: "A Fracture Mechanics Approach to the Tensile Strength Perpendicular to Grain of dimension Lumber". Wood Science and Technology, 7(1973), 45-59.

37. Madsen, B.: "Duration of Load Tests for Dry Lumber in Bending". Struct. Res. Series, Report No 3(1971). Civ. Eng. Dept., Univ. Brit. Columbia, Vancouver B.C., Canada.

38. Nielsen, L. Fuglsang and B. Madsen: "Fatigue at low frequencies of Douglas-Fir perpendicular to grain". Project made at Dept. Civil Engineering, Univ. British Columbia, Vancouver, B.C., Canada, 1983-88, Preliminary test report 1988, Build. Mat. Lab., Tech. Univ. Denmark.

39. Kraemer, O.: "Dauerbiegeversuche mit Hölzern". DVL-Jb. (1930), 411.

40. Le Govic, C.: "Creep in wooden structures: Creep in wood", Conference of Int. Union of Forestry Research Organizations (IUFRO), Saint John, New Brunswick, Fredericton, N.B., Canada, July 30 to August 3, 1990. Proc., Build. Mat. Lab., Techn. Univ. Denmark 1991.

41. Krebs, H.J.: "The influence of moisture content on the long term mechanical properties of wood" (in danish). Thesis, Build. Mat. Lab., Techn. Univ. of Denmark, 1984.

42. Schniewind, A.P. and Barrett, J.D.: "Wood as a linear orthotropic viscoelastic material". Wood Science and Technology, 6(1972).

43. Hoffmeyer, P.: "Failure of wood as influenced by moisture and duration of load". Thesis, Dept. Environmental Science and Forestry, State Univ. New York, Syracuse, N.Y. 1990.

44. Nielsen, L. Fuglsang: "Power-Law creep of wood - composite and dynamic aspects", Conference of Int. Union of Forestry Research Organizations (IUFRO), Bordeaux - France, 17.- 21. august, 1992. Proc., Build. Mat. Lab., Tech. Univ. Denmark, 1993, pp 25-33.

45. Idem: "Power-Law creep of wood - moisture variation aspects", Conference of Int. 
Union of Forestry Research Organizations (IUFRO), Bordeaux - France, 17.-21. august, 1992. Proc., Build. Mat. Lab., Tech. Univ. Denmark, 1993, pp 123-134.

46. Bach, L.: "Frequency-dependent fracture under pulsating loading". Build. Mat. Lab., Tech. Univ. Denmark, Tech. report 68, 1979, (presented at Forest Prod. Res. Society Annual Meeting 1975, Portland, Oregon, USA).

47. Marstrand, J.R. og C.N. Kristensen: "Limtræs udmattelsesstyrke". Eksamens-projekt ved Laboratoriet for Bygningsmaterialer, Danmarks tekniske Højskole, Juni 1993.

48. McNatt, J. D.: "Fatigue Properties of Three Particleboards in Tension and Interlaminar Shear". Forest Products Journ., 26(1976), 45 - 48.

49. Idem: "Design stresses for hardboard - effect of rate, duration, and repeated loading". Forest Products Journ., 20(1970), 53 - 60.

50. Ansell, M.P. and Tsai, K.T.: "Fatigue testing of wood composites for aerogenerator rotor blades". 6th BWEA conference 1984.

51. McNatt, J. D.: "Linear Regression of Fatigue Data". Wood Science, 11(1978), $39-41$.

52. Bohannan, B. and Kanvik, K.: "Fatigue Strength of Finger Joints". F.P.L., U.S.D.A., Rep. No. 114 (1969).

53. Clorius, C.O., Pedersen, M.U., Hoffmeyer, P., and Damkilde, L.: "Fatigue damage in wood", Proc., International COST 508 Wood Mechanics Conference, Stuttgart, Germany, may 14-16, 1996.

54. Ansell, M.P., Bonfield, P.W., and Tsai, K.T.: "Fatigue testing of laminated wood for generator blades", BWEA conference 1988 .

55. Madsen B. and Johns, K.: "Duration of Load Effects in Lumber:, Part I: A Fracture Mechanics Approach, Part II: Experimental Data, and Part III: Code Considerations", Can. J. Civ. Eng., 9(1982), 502-536.

56. Spencer, R.A. and Madsen, B.: "Duration of load tests for shear strength". Conference of Int. Union of Forestry Research Organizations (IUFRO), Xalapa, Mexico, December 1984. Proc., Build. Mat. Lab., Techn. Univ. Denmark 1985, 225 - 243.

57. Palmgren, A.: "Die Lebensdauer von Kugellagern, VDI, Zeitschrift Verein Deutscher Ingenieur, 68(1924), 339-341.

58. Miner, M.A.: "Cumulative damage in fatigue", Trans. ASTM, 67(1945), pp. A159A164.

59. Hashin, Z. and Rotem, A.: "A Fatigue Failure Criterion for Fiber-Reinforced Materials". Journ. of Composite Materials, 7(1973), 448 - 464.

60. Nielsen, L. Fuglsang: "Revnebevægelse i lineær-viskoelastiske materialer", (in danish, extensive english summary, Crack Propagation in Linear-Viscoelastic Materials), Bygningsstatiske Meddelelser, 49(1978), 1-45.

61. Idem: "Fatigue-styrken af beton og lignende viskoelastiske systemer med ældning", (in danish, Fatigue of concrete and other aging viscoelastic systems). Building Mat. Lab., Techn. Univ. Denmark, Technical Report 196(1989). 
62. Sørensen, N. Bo.: "Udmattelse af højstyrkebeton", (danish, Fatigue of high performance concrete), Ph.d.-thesis, Inst. Building Technic, Ålborg University, Denmark, 1993.

63. Nielsen, L. Fuglsang: "Træthed og reststyrke i beton og andre viskoelastiske materialer med ældning", (in danish, Fatigue and residual strength of concrete and other aging viscoelastic materials), Report R7(1996), Dept. Struct. Eng. and Materials, Tech. Univ. Denmark. 